\title{
Théâtres de Pompéi - Campagne 2016
}

Myriam Fincker, Éloöse Letellier-Taillefer et Stéphanie Zugmeyer

\section{(2) OpenEdition \\ Journals}

\section{Édition électronique}

URL : http://journals.openedition.org/cefr/1853

DOI : $10.4000 /$ cefr. 1853

ISSN : 2282-5703

\section{Éditeur}

École française de Rome

Référence électronique

Myriam Fincker, Éloïse Letellier-Taillefer et Stéphanie Zugmeyer, «Théâtres de Pompéi - Campagne

2016 », Chronique des activités archéologiques de l'École française de Rome [En ligne], Les cités vésuviennes, mis en ligne le 14 février 2018, consulté le 11 septembre 2019. URL : http:// journals.openedition.org/cefr/1853; DOI : 10.4000/cefr.1853

Ce document a été généré automatiquement le 11 septembre 2019.

(c) École française de Rome 


\title{
Théâtres de Pompéi - Campagne 2016
}

\author{
Myriam Fincker, Éloïse Letellier-Taillefer et Stéphanie Zugmeyer
}

\section{NOTE DE L'ÉDITEUR}

Éloïse Letellier-Taillefer (EFR) assure la coordination scientifique du projet. Myriam Fincker (IRAA) et Stéphanie Zugmeyer (IRAA) mènent l'analyse architecturale.

\section{NOTE DE L'AUTEUR}

Nous tenons à remercier les institutions qui rendent possibles les recherches menées dans le cadre du projet Teatri di Pompei : Parco archeologico di Pompei, EFR - Centre Jean Bérard, IRAA. Nous adressons en particulier nos plus vifs remerciements à la Surintendance de Pompéi : au Surintendant Massimo Osanna, à Grete Stefani, directrice des fouilles, à Laura D'Esposito, fonctionnaire responsable de la regio VIII ainsi qu'à Raffaele Martinelli, architecte, pour le soutien qu'ils ont bien voulu accorder à ce nouveau projet de recherche et le support fourni pendant les campagnes de terrain. Il nous est également agréable de remercier Guilhem Chapelin, Thomas Crognier et Dominique Leconte pour leur aide.

\section{Introduction}

1 Le projet Teatri di Pompei se donne pour objectif de développer une nouvelle étude monographique conjointe du grand théâtre et du theatrum tectum (théâtre couvert) de Pompéi. Ces deux édifices, érigés l'un à côté de l'autre dans la partie méridionale de la ville, furent découverts dès le début des fouilles, respectivement en juillet 1764 et mars 1769 , puis dégagés progressivement, de 1765 à $1795^{1}$ (fig. 1). Ils ont depuis lors et jusqu'à récemment subi d'importantes restaurations. Les nombreux antiquaires, 
architectes et touristes qui les ont visités depuis le $\mathrm{XVIII}^{\mathrm{e}} \mathrm{s}$. ont produit une riche documentation à leur sujet.

Fig. 1 - Premier plan connu du quartier des théâtres en cours de fouille, par Jean-Augustin Renard en 1778 (Saint-Non 1782, pl. 84).

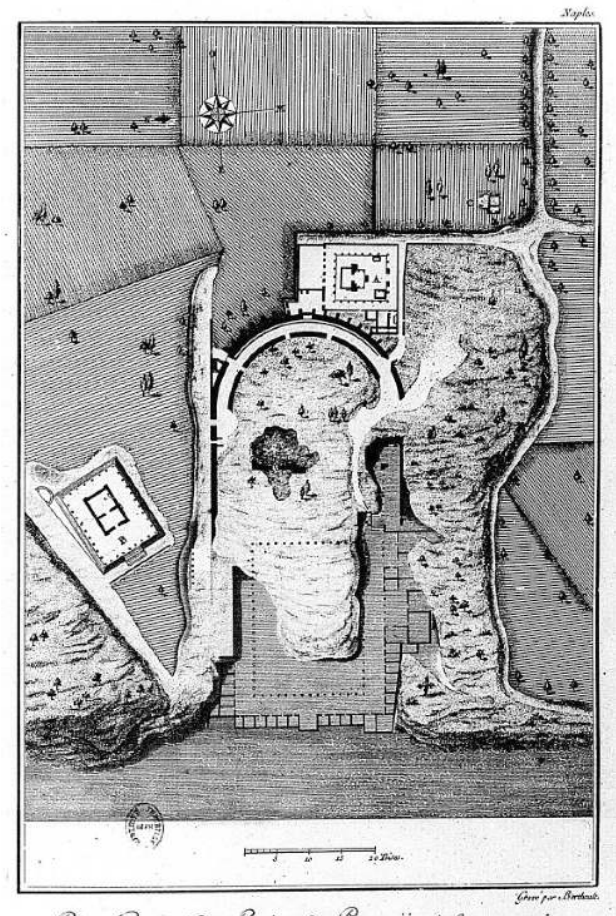

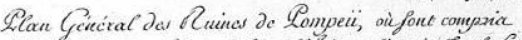

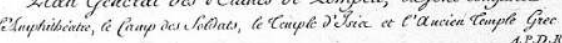

Source de l'image : gallica.bnf.fr/BnF

Bâtis entre la période samnite et la fondation coloniale de Pompéi au cœur d'un quartier largement voué aux activités publiques, en lien direct avec le forum triangulaire, les sanctuaires urbains de Minerve et Hercule, d'Isis et d'Esculape, la palestre samnite et le grand quadriportique (fig. 2), ces théâtres jouent un rôle fondamental dans l'histoire urbaine du site. Par ailleurs, ils sont souvent considérés comme des cas exemplaires dans les travaux de synthèse sur l'architecture théâtrale antique : le grand théâtre fait figure de modèle du passage d'une forme architecturale « de type grec » à une forme « de type latin » et le theatrum tectum compte parmi les exemples incontournables pour aborder la typologie problématique des «odéons ». Pourtant ces deux monuments n'ont jamais été soumis à une étude systématique complète et les connaissances à leur sujet demeurent très lacunaires ${ }^{2}$.

Fig. 2 - Plan de situation de l'insula VIII 7 avec les édifices publics voisins des théâtres, d'après les RICA Maps. Les numéros en bleu correspondent aux numéros d'entrée conventionnels mentionnés dans le texte (le nord est conventionnellement placé en haut de l'image). 


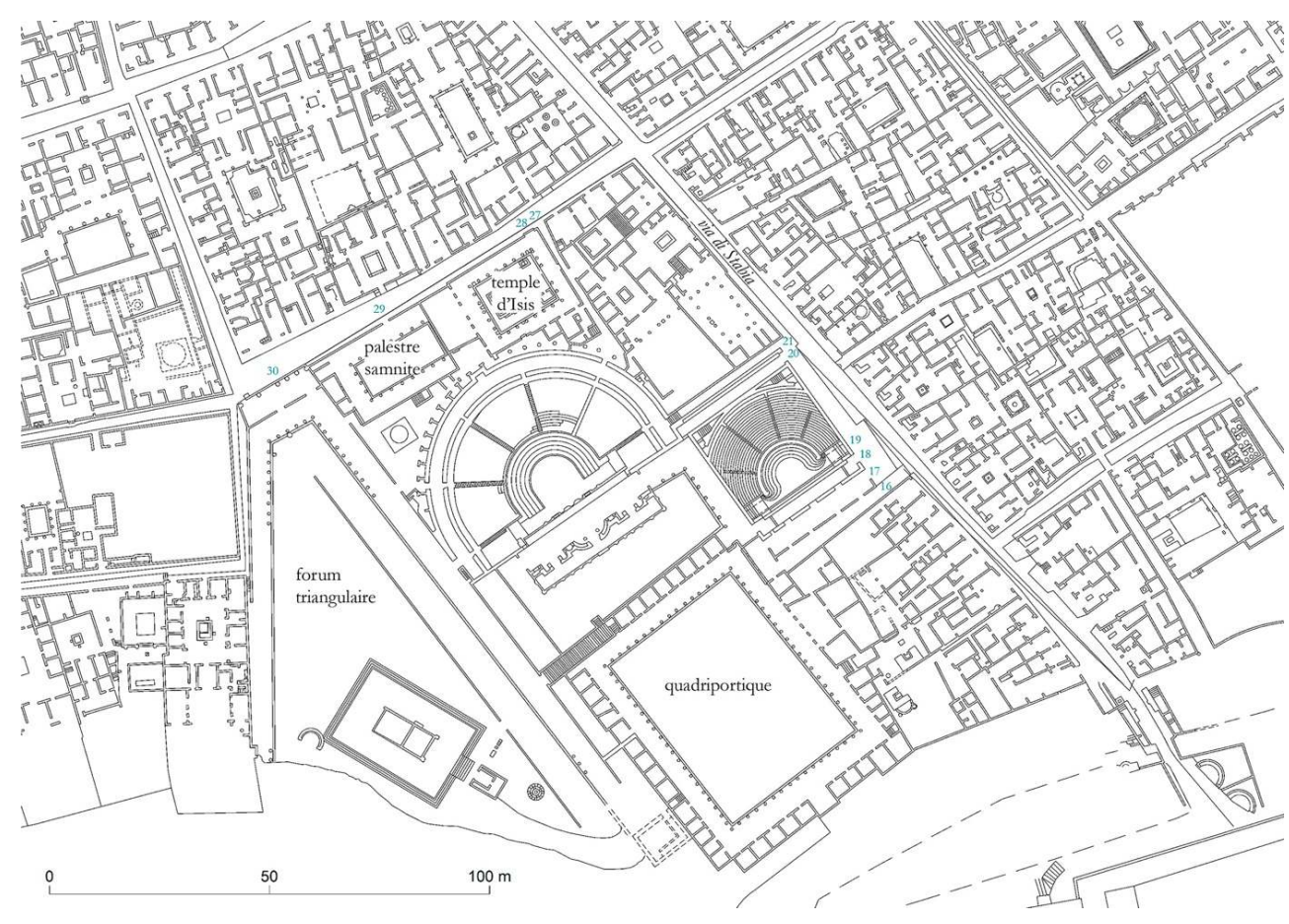

É. Letellier-Taillefer.

\section{Un aperçu sur l'histoire des recherches}

Le grand théâtre a fait l'objet de quelques campagnes de fouilles au $x x^{e} s .^{3}$ avant de subir des travaux de restauration destinés à y organiser des spectacles ${ }^{4}$. La chronologie de cet édifice demeure débattue et pour une large part incertaine; si la succession des états du bâtiment de scène et celle des transformations de la cavea, repérés par A. Mau et précisés par A. Maiuri, apparaissent plausibles, la correspondance entre les différentes phases des deux composantes demeure problématique, ainsi que leur datation. Dans l'état actuel des connaissances, on estime que le théâtre fut bâti à l'époque samnite, sans qu'il soit encore possible de préciser à quelle date. Il fut ensuite remanié - peut-être plusieurs fois - avant une transformation de grande ampleur dont la date augustéenne est assurée par l'épigraphie ${ }^{5}$. Le front de scène subit enfin une dernière reconstruction, en terre cuite, après le séisme qui ébranla la ville en 63 apr. J.-C.

Depuis les années 1950, si le théâtre est évoqué dans les travaux de synthèse sur Pompéi ou les travaux consacrés aux théâtres romains, aucune nouvelle étude approfondie n'a été publiée à son sujet. D'importantes restaurations ont été effectuées en 2009-2010 dans le but d'accueillir de nouvelles représentations dramatiques et lyriques (fig. 3). Des spécialistes d'acoustique se sont penchés sur ce théâtre, sans disposer cependant d'une étude architecturale assez précise ${ }^{6}$. 
Fig. 3 - Vue du grand théâtre de Pompéi en 2014 (après la restauration des gradins de 2010). A : tribune latérale ; B : proédrie ; C : ima cavea ; D : summa cavea.

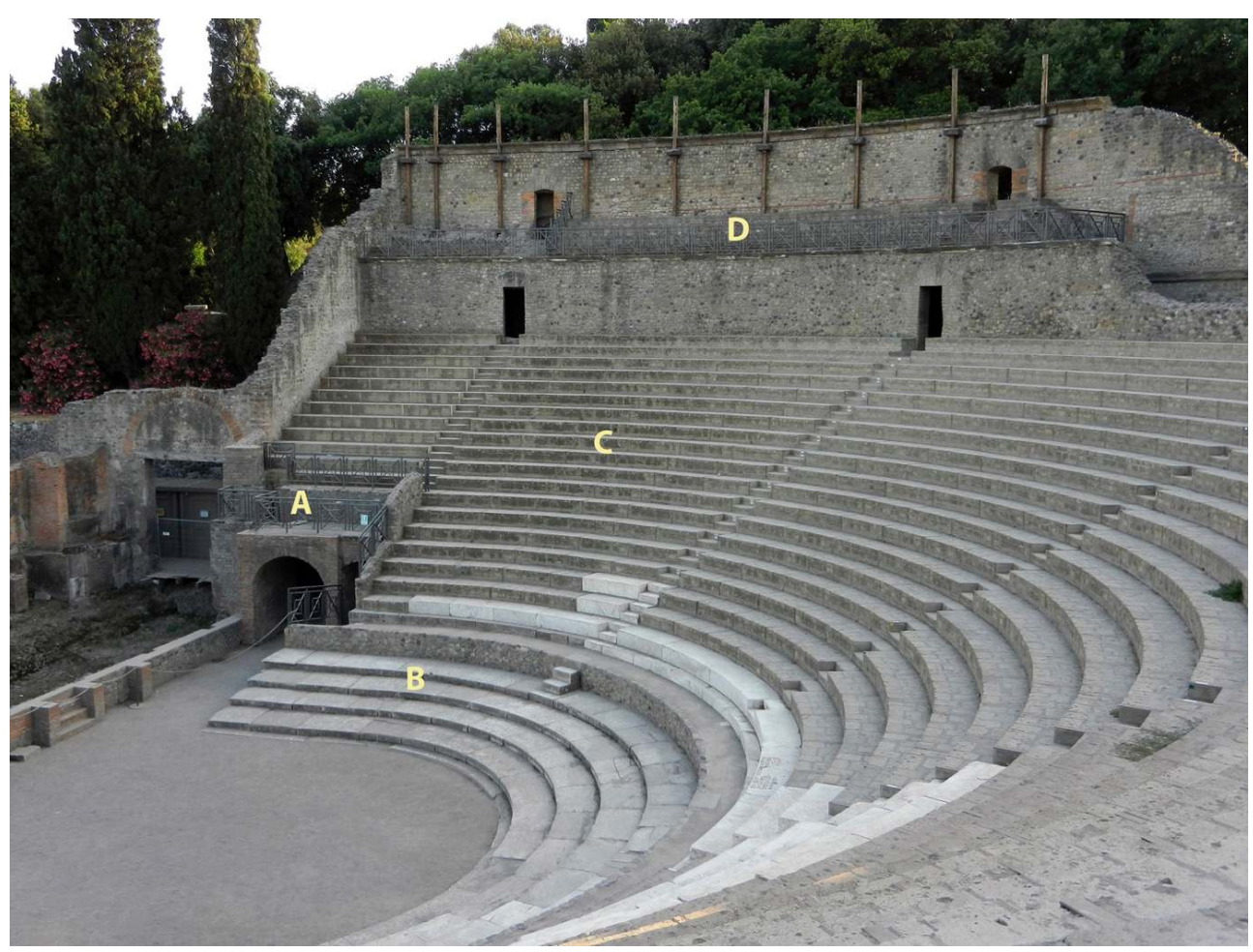

Cl. É. Letellier-Taillefer. Avec l'aimable autorisation de la Surintendance de Pompéi.

Le theatrum tectum n'a jamais fait l'objet d'investigations stratigraphiques; seuls quelques articles lui ont été consacrés dans la première partie $d u x^{e} s^{7}$. Ses gradins ont également été restaurés pour l'organisation de spectacles modernes ${ }^{8}$. L'inscription de dédicace conservée en deux exemplaires sur ses façades indique indubitablement une date au début de la période coloniale de Pompéi, dans les années 80-70 av. J.-C. ${ }^{9}$. On considère dès lors généralement qu'il s'agit d'une construction homogène, entièrement bâtie à cette époque. Cependant, plusieurs éléments apparaissent problématiques au regard d'un tel contexte, notamment la mobilisation très claire de modèles architecturaux et décoratifs attestés dans des édifices de date nettement antérieure. La fonction - spectaculaire ou politique - de cette salle couverte n'a jamais pu être tranchée ${ }^{10}$. La question de son acoustique, importante pour envisager ce problème, a été abordée en $2007^{11}$; cependant, comme pour le grand théâtre, il faudrait pouvoir l'appuyer sur une enquête architecturale préalable.

Plusieurs campagnes de documentation de la zone des théâtres ont été effectuées récemment. En 2013, un projet d'expérimentation des méthodes d'aéro-photogrammétrie par drone a choisi le quartier des théâtres de Pompéi comme terrain d'application en raison de l'intérêt historique de cette zone et des particularités de sa topographie ${ }^{12}$. Par ailleurs, dans le cadre du Piano della Conoscenza du Grande Progetto Pompei, la Surintendance de Pompéi a fait effectuer ortho-photographies, relevés au laser-scanner, plans et coupes au $1 / 50$ et modèle 3D de toute l'insula VIII 7. 


\section{Présentation du projet Teatri di Pompei et résultats préliminaires de la campagne de terrain 2016}

7 Cette situation documentaire rend à la fois possible et nécessaire une nouvelle étude des deux théâtres de Pompéi qui réponde aux exigences actuelles des recherches sur l'architecture antique. Nous avons choisi d'englober les deux édifices dans la même enquête : nous pensons en effet qu'un tel choix favorisera les déductions chronologiques, puisque les deux bâtiments sont directement liés et partagent plusieurs accès. Il permettra également d'effectuer les comparaisons précises entre les solutions architecturales développées dans chacun des deux édifices et d'interroger d'éventuels transferts d'innovations.

8 Nos recherches poursuivent les quatre objectifs suivants :

- documenter leur état actuel ;

- distinguer les vestiges antiques des restaurations modernes;

- préciser la chronologie de chacun des édifices ainsi que celle de leur association en un " quartier des théâtres »;

- analyser leur place au sein du quartier et de la ville.

9 Dans ce but, nous travaillons dans deux directions complémentaires: l'analyse de la documentation moderne, qui permet de retracer l'histoire de la redécouverte et des restaurations des deux théâtres et une nouvelle étude du bâti conservé, qui procèdera par étapes et par investigations thématiques.

10 Cette analyse architecturale a été initiée lors d'un séjour préparatoire sur le site en avril 2016 puis d'une campagne de terrain de deux semaines, du 17 au 30 octobre 2016. Nos premières investigations ont porté sur les aditus et tribunes latérales de chacun des deux théâtres. Ces espaces, situés au contact de la cavea et du bâtiment de scène, nous ont en en effet semblé particulièrement parlants pour aborder l'histoire architecturale des édifices. Ils sont d'autant plus importants à Pompéi qu'ils pourraient figurer parmi les exemples les plus précoces d'accès latéraux couverts, élément architectural considéré comme un des marqueurs du modèle de théâtre de type latin.

\section{Le grand théâtre}

11 La dernière configuration de la cavea du théâtre date de la fin de la période augustéenne (entre 2 av. J.-C. et 14 apr. J.-C.), comme l'indiquent les inscriptions mentionnant Marcus Holconius Rufus et Marcus Holconius Celer qui financèrent, sur leur fonds personnels, « cryptam, tribunalia, theatrum $»^{13}$. Depuis cette date, l'espace réservé au public se divise en quatre zones: les tribunes latérales situées au-dessus des aditus (fig. $3 \mathrm{~A}$ ), quatre degrés de proédrie bordant l'orchestra (fig. 3 B), les 19 rangs de gradins de l'ima cavea (fig. $3 \mathrm{C}$ ) à la fois isolée et desservie, en bas, par une précinction et, en haut, par un couloir périphérique couvert que les inscriptions nous conduisent à désigner par le nom de crypta ; enfin, au-dessus de cette dernière furent installés les quatre rangs de gradins de la summa cavea (fig. 3 D).

12 Les gradins étaient accessibles d'une part par le niveau haut du quartier, en empruntant l'une des portes ouvertes dans l'aile orientale du portique du forum triangulaire, en longeant le sanctuaire d'Isis par la ruelle VIII 7, 27 ou encore en gravissant la 
rampe VIII 7, 21 depuis la via di Stabia. D'autre part, par le niveau bas, on pouvait emprunter les aditus, accessibles par le couloir VIII 7, 20 ou par le portique en L reliant les deux théâtres pour l'aditus oriental, par la cour située à l'arrière du bâtiment de scène pour l'occidental (les numéros d'entrées cités sont indiqués en bleu sur la fig. 2).

Dans le grand théâtre, nos recherches se sont concentrées sur l'aditus occidental, moins touché que son symétrique par les effondrements et les restaurations modernes, et où peuvent être observées assez clairement les dernières phases antiques de construction et de transformations de la cavea. Nous ne traitons pas ici de la phase originelle du théâtre, repérée par A. Mau ${ }^{14}$ puis par A. Maiuri ${ }^{15}$; dans ce premier théâtre, dont on ne connaît pas le bâtiment de scène, les accès latéraux à l'orchestra étaient découverts, comme le sont les parodoi des théâtres grecs. Ces accès découverts étaient situés plus au nord que les aditus des phases ultérieures, sur lesquels ont porté nos observations.

Fig. 4 - Modèle axonométrique schématique de l'aditus occidental du grand théâtre avec dénomination des espaces.

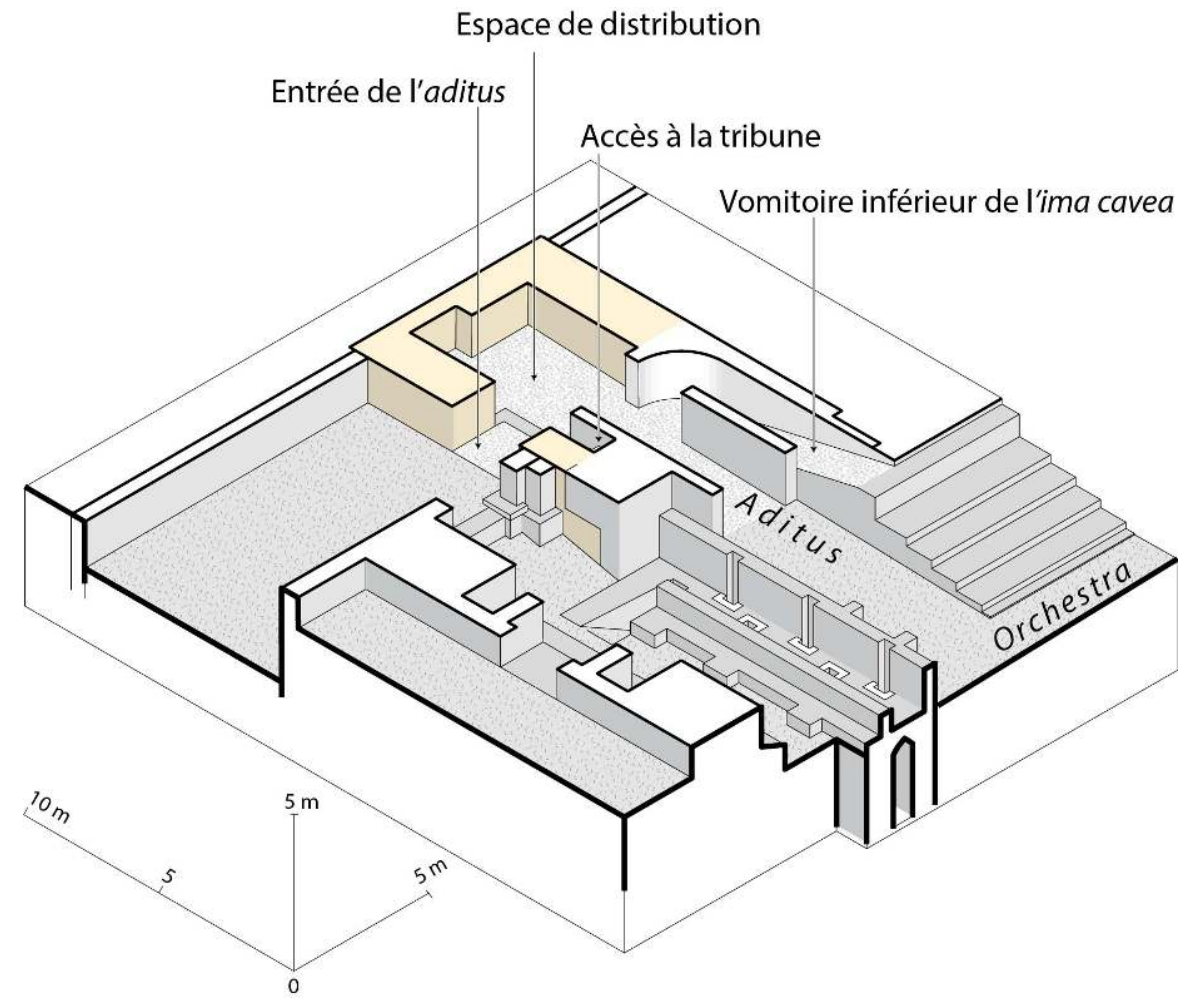

(c) IRAA/EFR. Relevés et dessin M. Fincker.

L'aditus occidental du grand théâtre (fig. 4) est actuellement composé d'un " espace de distribution ", auquel on accède depuis «l'entrée », située au sud. Vers l'est, cet espace dessert, du nord au sud, le " vomitoire inférieur de l'ima cavea », le " débouché de l'aditus dans l'orchestra » et "l'accès à la tribune ». L'aménagement de l'espace avec ces trois accès distincts correspond au dernier état de l'aditus. Leur installation a en effet considérablement modifié la situation antérieure dans toute la partie occidentale. Pour plus de clarté, nous décrivons successivement les deux états actuellement repérés de cet aditus. 


\section{État 1 de l'aditus}

15 C'est dans la façade rectiligne de la cavea qu'on peut observer plusieurs indices révélant l'extension du premier état.

16 Dans cette façade, entre le mur de retour du bâtiment de scène et le mur de la solide terrasse établie à un niveau intermédiaire entre le forum triangulaire et le théâtre, s'ouvre l'entrée de l'aditus (fig. 5a). Cette porte, de 2,51 m de large, est couverte d'un arc surbaissé de $80 \mathrm{~cm}$ de flèche dont la clé est formée par un grand voussoir en tuf, orné d'une tête sculptée à la chevelure longue et bouclée (fig. $\mathbf{5 b}$ ). Le reste de l'arc est constitué d'une maçonnerie de moellons de lave de dimensions beaucoup plus modestes ${ }^{16}$ : il est donc difficile de déterminer, dans l'état actuel de nos observations, si ce voussoir est ici en position initiale ou en remploi. Tout raisonnement appuyé sur une analyse stylistique de cette sculpture pour dater la construction de l'aditus (et donc la deuxième phase de la cavea du grand théâtre de Pompéi) doit donc être considéré avec beaucoup de prudence.

Fig. 5a - Photographie de l'entrée de l'aditus occidental du grand théâtre de Pompéi en 1906, lors des fouilles dirigées par $A$. Mau.

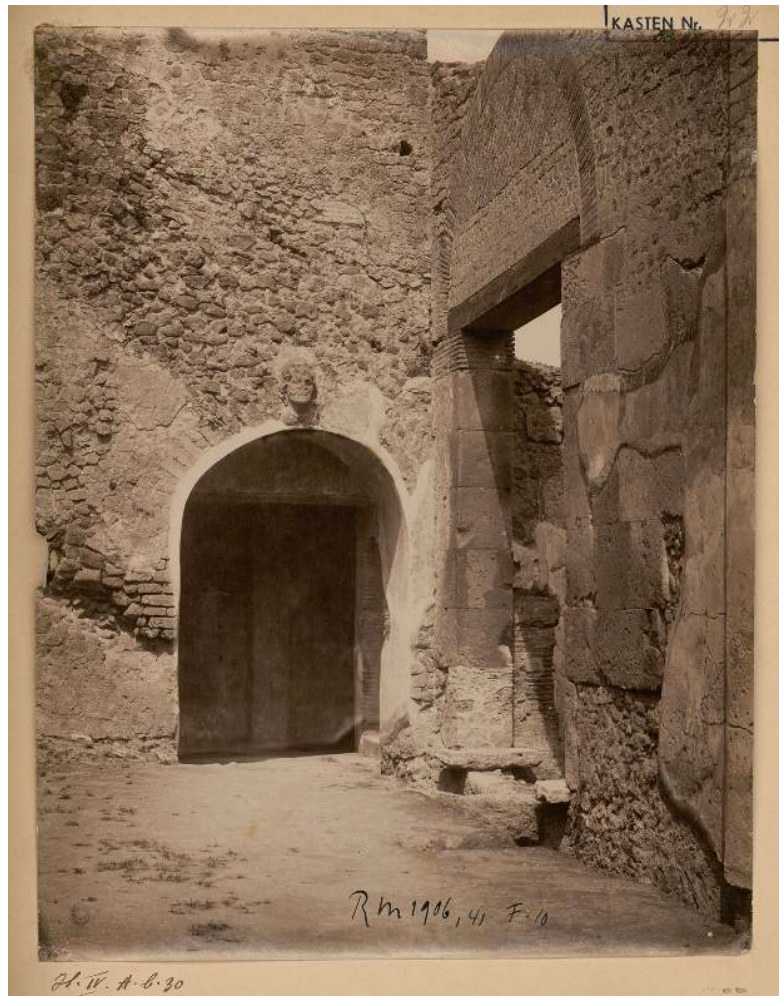

(C) Bibliothèque numérique patrimoniale du Service Commun de la Documentation de l'Université de Strasbourg 
Fig. 5b - Clé d'arc en tuf de l'entrée de l'aditus occidental du grand théâtre de Pompéi (haut. : $82 \mathrm{~cm}$ ).

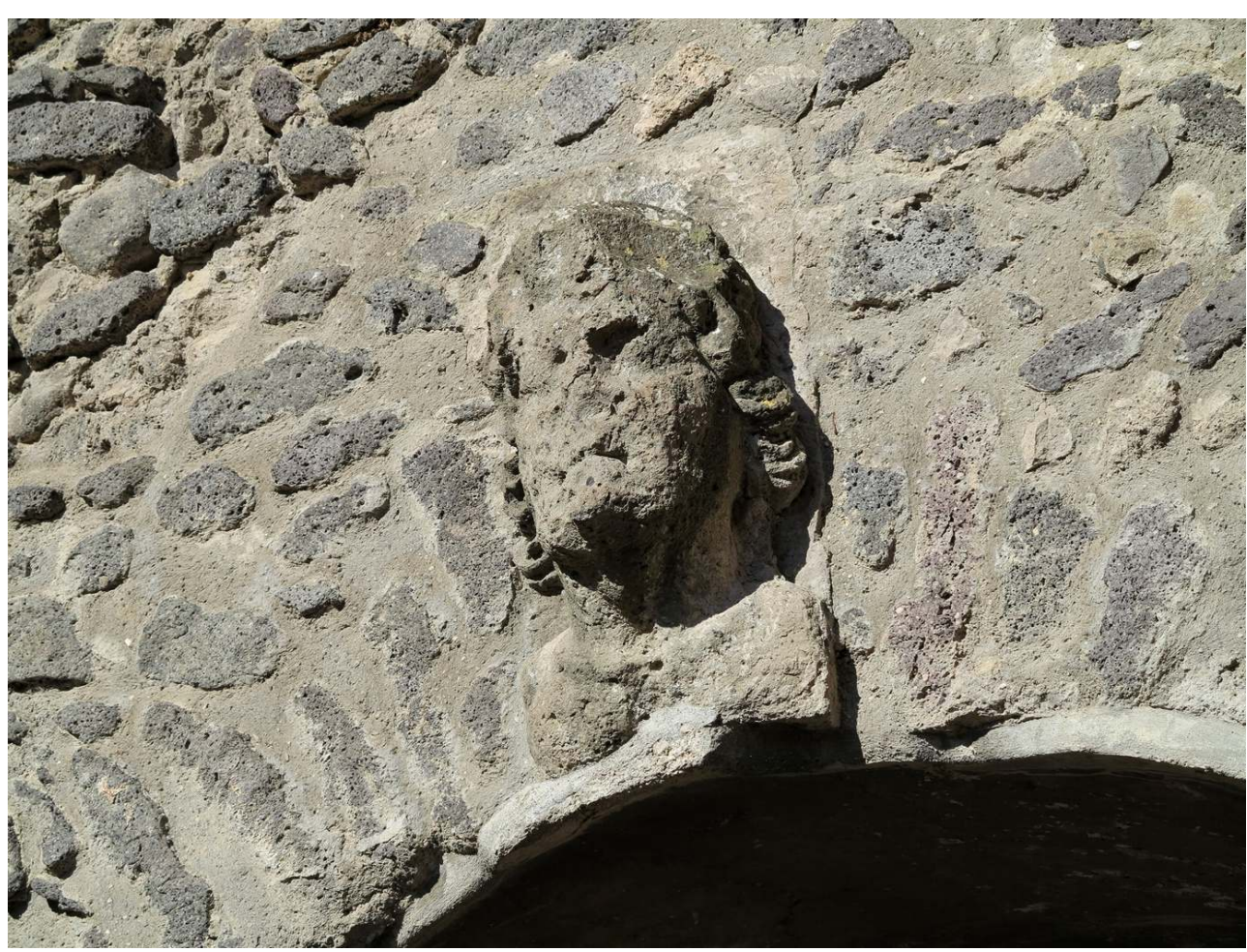

Cl. EFR/IRAA. Avec l'aimable autorisation de la Surintendance de Pompéi.

17 L'entrée de l'aditus est ménagée dans un mur constitué d'une maçonnerie de moellons irréguliers de lave, disposés parfois en assises horizontales et plus souvent de manière irrégulière. La limite occidentale de ce mur est située à $6,50 \mathrm{~m}$ par rapport au mur de retour du bâtiment de scène et coïncide approximativement avec l'extension de la terrasse intermédiaire (fig. 6).

18 La partie de la façade de la cavea située à l'ouest de cette limite correspond à une phase d'agrandissement successive, venue s'appuyer sur le mur du premier état. La partie haute de la façade, majoritairement constituée de moellons de calcaire du Sarno de dimensions variables, est issue de restaurations modernes. On note que la restauration moderne présente une rupture située dans l'alignement vertical de la limite entre les deux états. 
Fig. 6 - Partie occidentale de la face sud de l'aditus occidental du grand théâtre de Pompéi. Vue générale et repérage des états successifs.

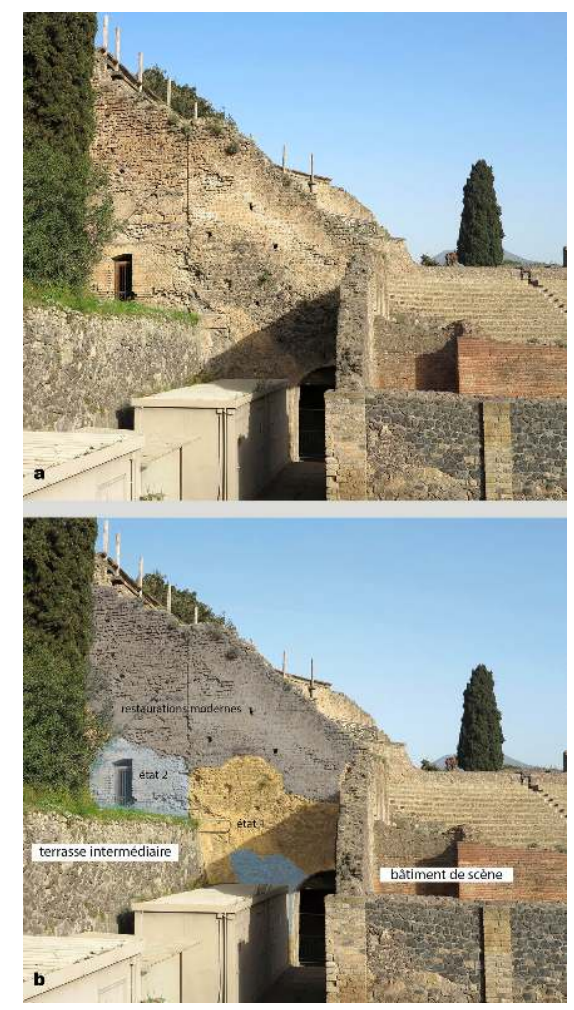

Cl. EFR/IRAA. Avec l'aimable autorisation de la Surintendance de Pompéi.

19 Approximativement à la hauteur de la terrasse et dans l'alignement de son mur de soutènement, dans le chaînage d'angle marquant la limite occidentale du mur en lave sont insérés deux blocs de grand appareil de calcaire du Sarno placés en boutisse et panneresse (fig. 6-7). 
Fig. 7 - Vue de détail de la limite entre les deux états visibles de la façade sud de la cavea du grand théâtre de Pompéi.

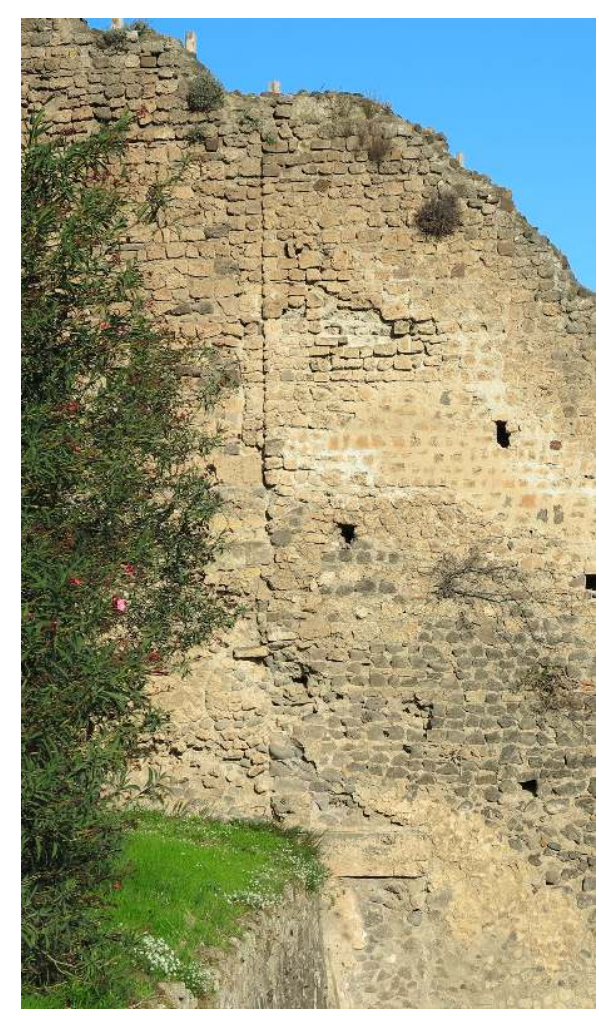

Cl. EFR/IRAA. Avec l'aimable autorisation de la Surintendance de Pompéi.

De l'autre côté du mur de retour du bâtiment de scène, on observe l'extrémité orientale de la face sud du premier état de l'aditus. Elle est matérialisée, dans la partie supérieure, par la limite verticale de la construction en maçonnerie de lave, sur laquelle vient s'appuyer la maçonnerie en tuf de la tribune, installée dans l'état successif (voir plus bas, état 2) (fig. 8). En partie haute, on observe un bloc de calcaire du Sarno appartenant probablement au chaînage d'angle de ce mur. Cet axe vertical ne semble pas issu d'une retaille et matérialise très probablement l'alignement de la façade du débouché de l'aditus dans l'orchestra dans ce premier état. Il est d'ailleurs situé sur le même plan qu'un décrochement visible dans la maçonnerie de la voûte du vomitoire installé dans l'état 2, qui ne s'explique que par cette limite préexistante (voir la coupe AA sur la fig. 15).

21 En partie basse, l'extrémité orientale de la face sud du premier état de l'aditus est située plus en avant et clairement marquée par le retour d'un revêtement enduit sur l'angle ( fig. 8-9). 
Fig. 8 - Extrémité orientale de la face sud de l'aditus occidental du grand théâtre de Pompéi. Vue d'ensemble et repérages des états successifs.

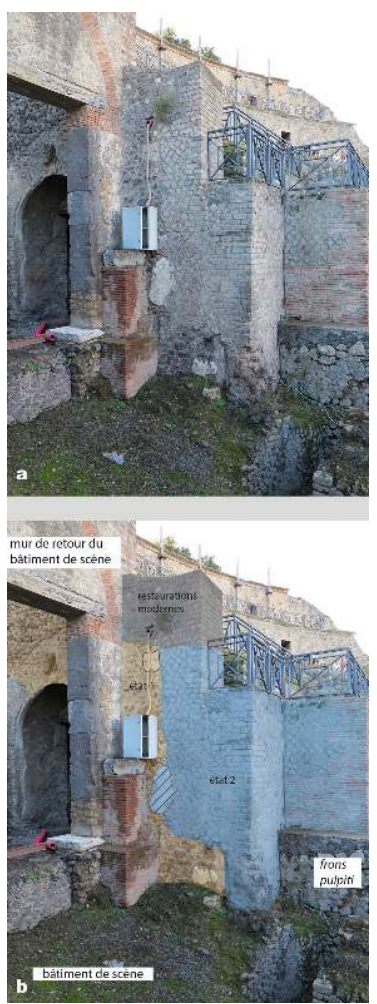

Cl. EFR/IRAA; DAO É. Letellier-Taillefer. Avec l'aimable autorisation de la Surintendance de Pompéi

Fig. 9 - Conservation de l'enduit sur l'angle inférieur du mur en maçonnerie de lave correspondant à l'état 1 de l'aditus occidental de Pompéi (vue du sud).

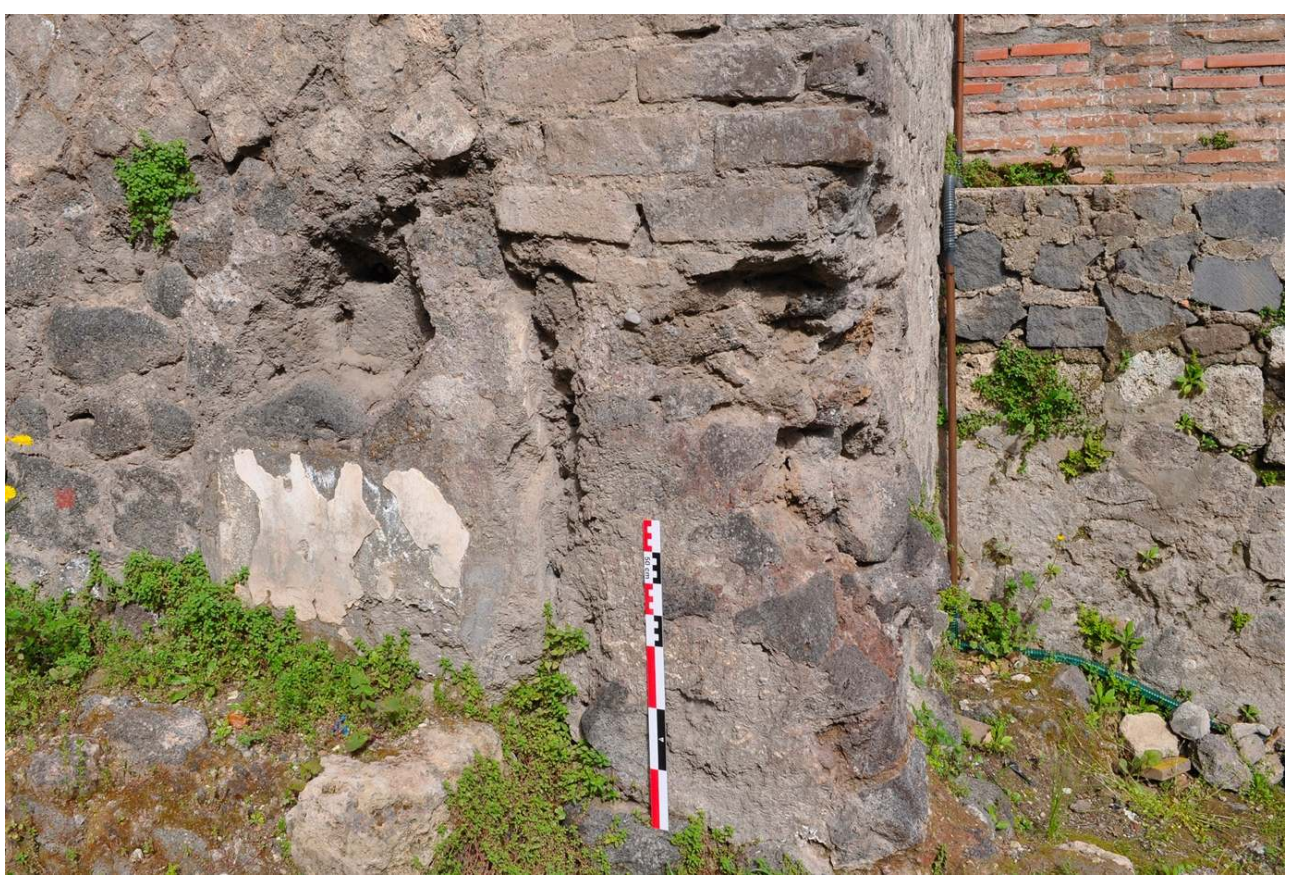

CI. IRAA/EFR. Avec l'aimable autorisation de la Surintendance de Pompéi. 
Une fois passée l'entrée de l'aditus, dont les montants ont, dans ce premier état, une largeur de $1,76 \mathrm{~m}$, on aboutit dans une salle de plan globalement rectangulaire (long. = $6,91 \mathrm{~m}$; larg. = 3,80 m) couverte par une voûte rampante maçonnée et enduite, en pente vers l'orchestra. Dans ce premier état, il ne s'agit pas encore d'un véritable «espace de distribution " puisque cette salle ne débouche alors que dans l'orchestra, probablement à $2,10 \mathrm{~m}$ en retrait par rapport à la façade du débouché actuel (fig. 10).

Fig. 10 - Modèles axonométriques schématiques de l'état 1 de l'aditus occidental du grand théâtre de Pompéi.

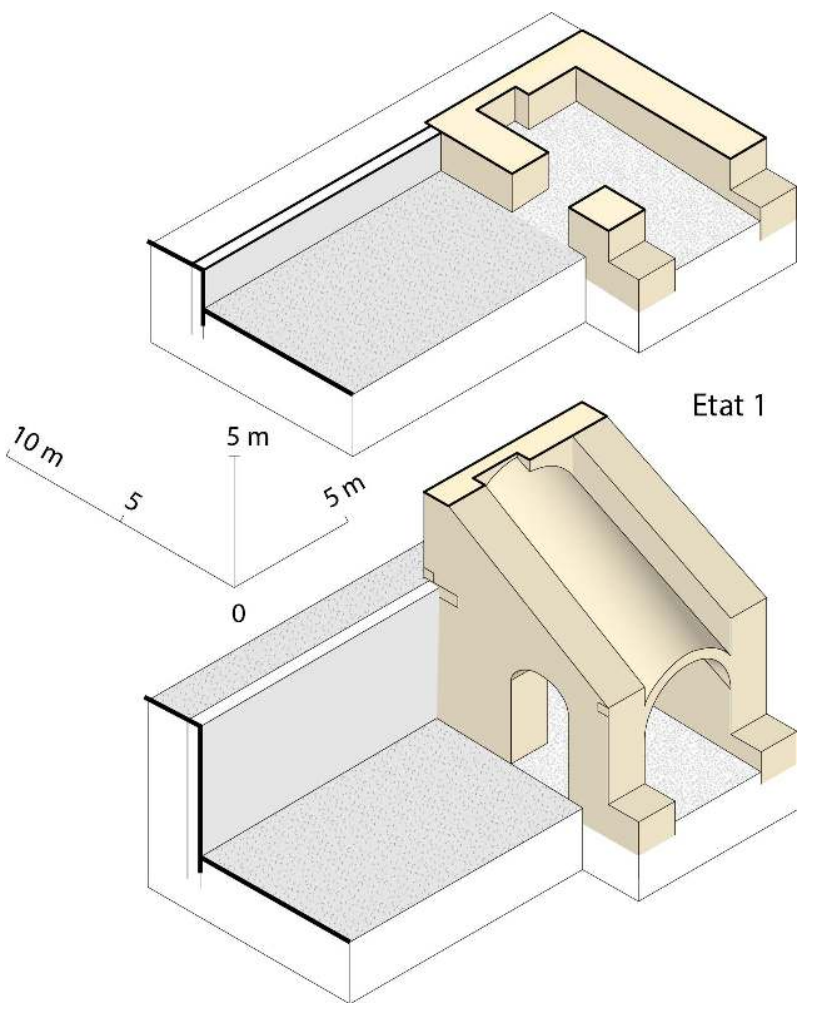

(C) IRAA/EFR. Relevés et dessin M. Fincker.

La paroi occidentale de cet espace (fig. 11), adossée au relief sur lequel s'étend le forum triangulaire, présente un fruit de $20 \mathrm{~cm}$ env. On y observe un ressaut vers l'intérieur, sur $2,10 \mathrm{~m}$, dans la moitié nord. Ce ressaut est formé par un mur de $63 \mathrm{~cm}$ d'épaisseur maximale, qui présente également un fruit, vers l'ouest et vers le nord. Cet aménagement spécifique répond certainement à des contraintes statiques, notamment pour contenir les poussées du terrain, probablement en pente à l'origine et en partie excavé pour aménager le niveau de circulation autour du théâtre. L'ensemble de cette paroi occidentale est revêtu, en partie basse, d'un enduit réalisé d'un seul tenant, sur lequel s'appuient les enduits des parois nord et sud. Là où l'enduit a disparu, on peut observer que le mur est constitué d'une maçonnerie de moellons de lave avec quelques blocs de calcaire du Sarno, employés notamment pour aménager l'angle du ressaut. 
Fig. 11 - Paroi occidentale de l'espace de distribution de l'aditus occidental du grand théâtre, vue depuis l'est et départ de la voûte en pente vers l'orchestra.

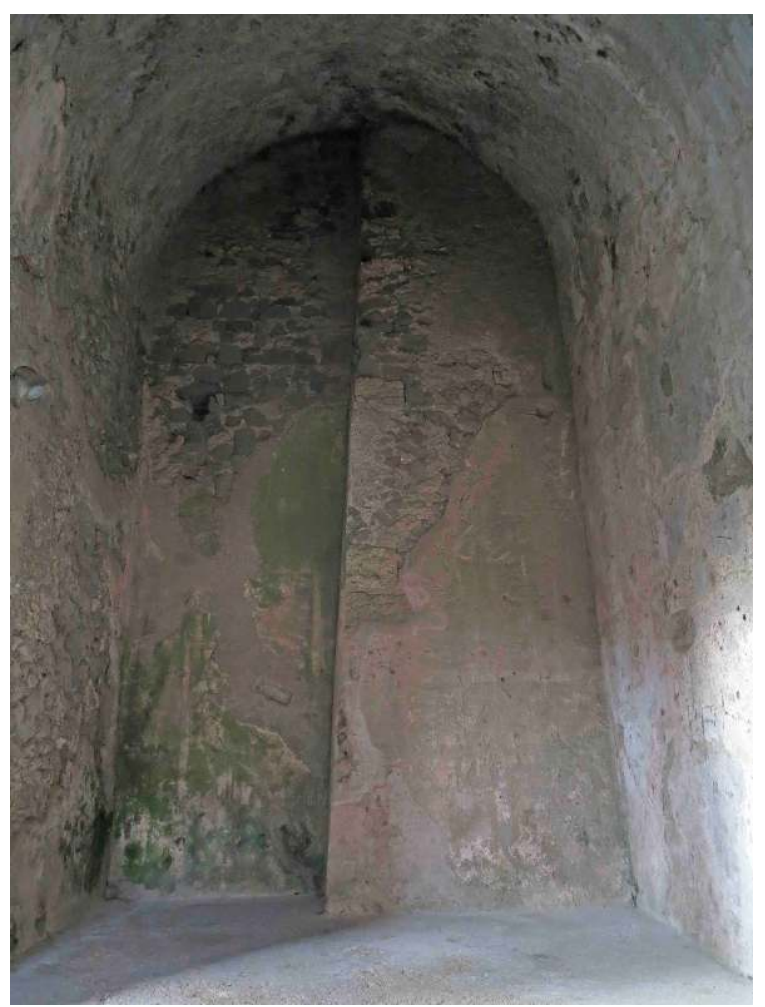

Cl. EFR/IRAA. Avec l'aimable autorisation de la Surintendance de Pompéi

\section{État 2 de l'aditus}

Le deuxième état visible de l'aditus correspond à l'agrandissement et à la transformation du théâtre financés par les Holconii à l'époque augustéenne. L'agrandissement, avec la construction de la summa cavea, s'observe en particulier dans la façade sud de l'aditus, au niveau de la terrasse intermédiaire (fig. 6). La porte accessible depuis cette terrasse

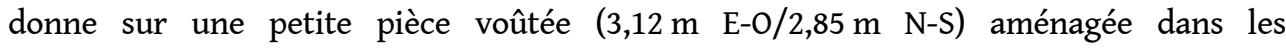
substructions de la cavea agrandie et dont la vocation est encore inconnue ${ }^{17}$. Peut-être cet espace creux en arrière de la paroi occidentale de l'aditus servait-il uniquement à décharger ce mur de la poussée du terrain? La maçonnerie de cette partie de la façade, composée de moellons de lave, calcaire et tuf sans assises régulières, avec aménagement de l'ouverture en appareil régulier de moellons rectangulaires de tuf, rappelle les techniques de construction employées dans la façade semi-circulaire de la cavea augustéenne.

La partie orientale de l'aditus subit un important remaniement, lié à l'installation du tribunal $^{18}$ (fig. $3 \mathrm{~A}$ ) et à l'aménagement d'un triple accès à l'intérieur du théâtre, avec, du nord au sud, le vomitoire inférieur de l'ima cavea, le débouché de l'aditus dans l'orchestra, et l'accès à la tribune (fig. 12). 
Fig. 12 - Vue depuis l'ouest du triple accès à l'intérieur du théâtre aménagé dans l'état 2 de l'aditus occidental.

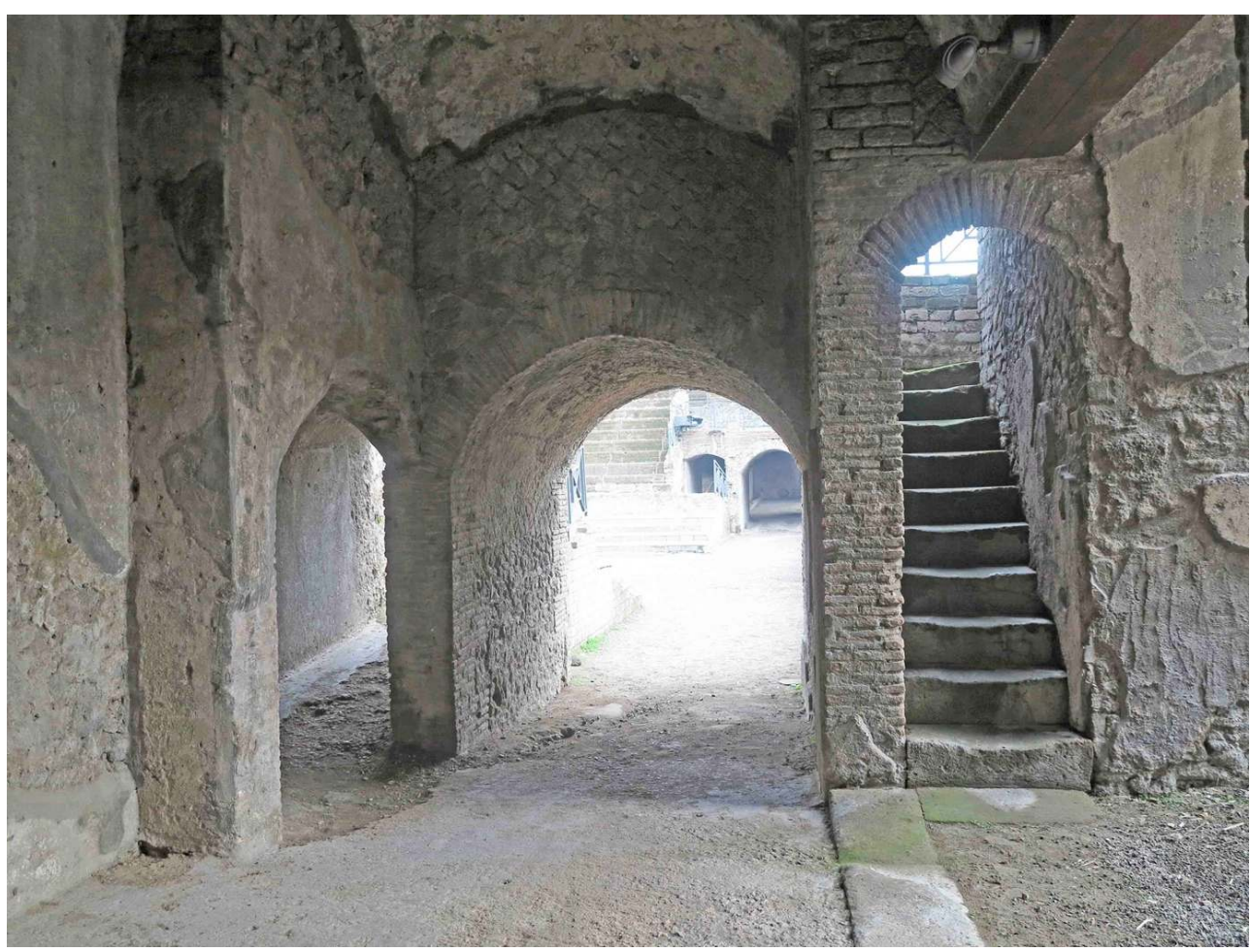

Cl. EFR/IRAA. Avec l'aimable autorisation de la Surintendance de Pompéi.

Fig. 13 - Aménagement en sous-œuvre de l'accès à la tribune et du débouché dans l'orchestra.

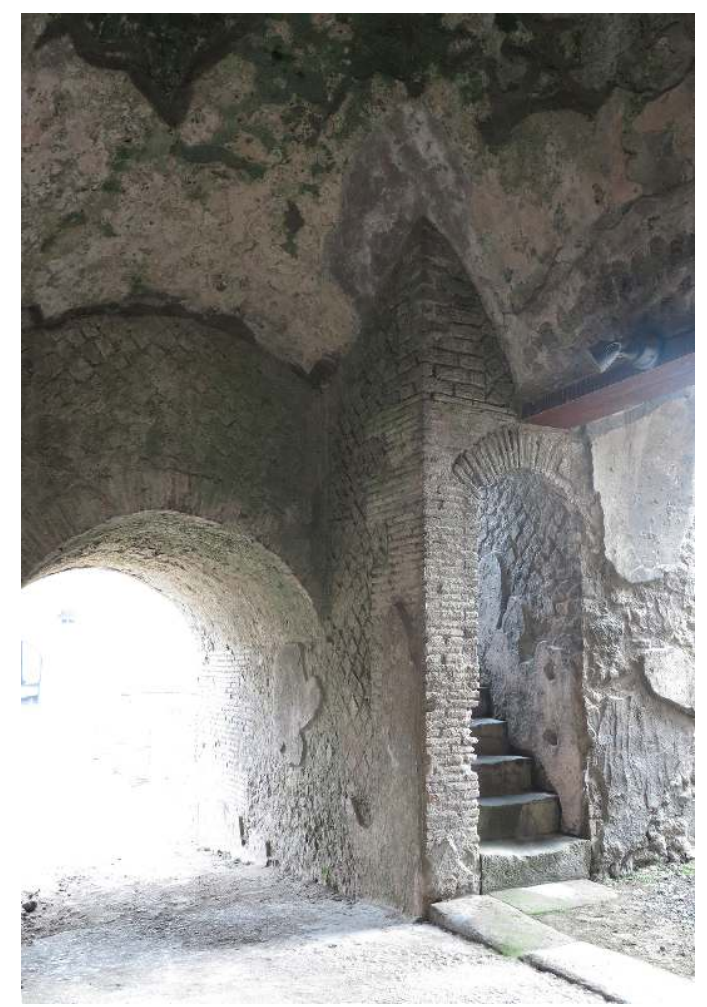

Cl. EFR/IRAA. Avec l'aimable autorisation de la Surintendance de Pompéi. 
Les couvrements voûtés de ce triple accès sont appuyés en sous-œuvre contre la voûte rampante de l'état 1 , largement préservée. Leurs maçonneries, en moellons de tuf disposés en appareils irrégulier ou réticulé selon les endroits, avec chaînages à harpes, en moellons de tuf rectangulaires en assises régulières ou en terre cuite, s'appuient très clairement contre l'enduit de la voûte préexistante (fig. 12-13). L'état 1 de l'aditus se retrouve donc englobé dans le nouvel aditus, plus étendu en direction de l'orchestra et supportant le nouveau tribunal (fig. 14-15).

Fig. 14 - Modèles axonométriques schématiques de l'aditus occidental du grand théâtre de Pompéi. Le premier état conservé dans le remaniement augustéen est mis en évidence en jaune.

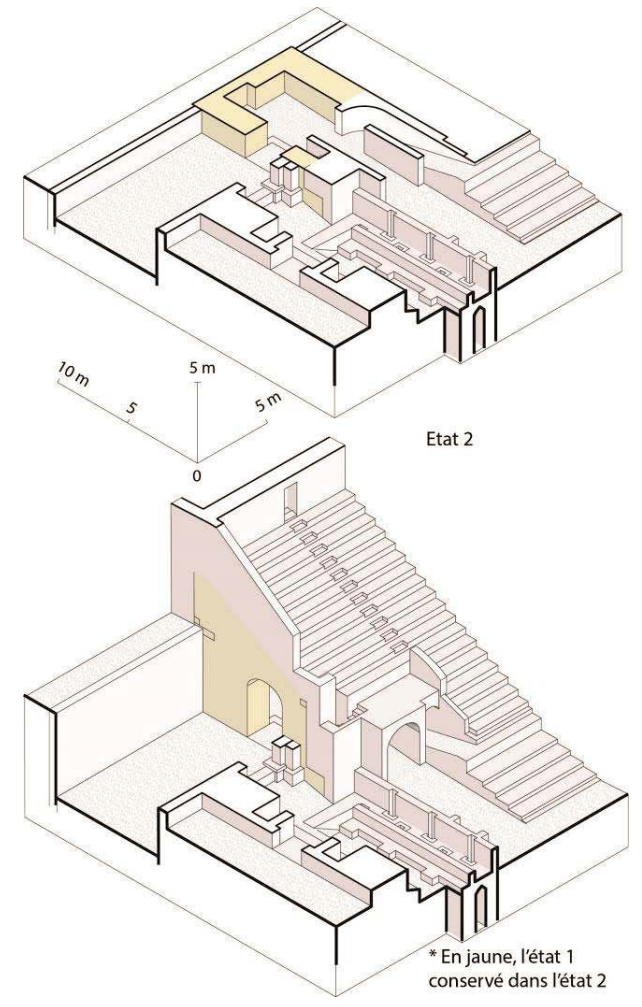

(C) IRAA/EFR. Relevés et dessin M. Fincker. 
Fig. 15 - Coupes sur chacun des trois accès aménagés dans l'état 2 de l'aditus du grand théâtre de Pompéi.

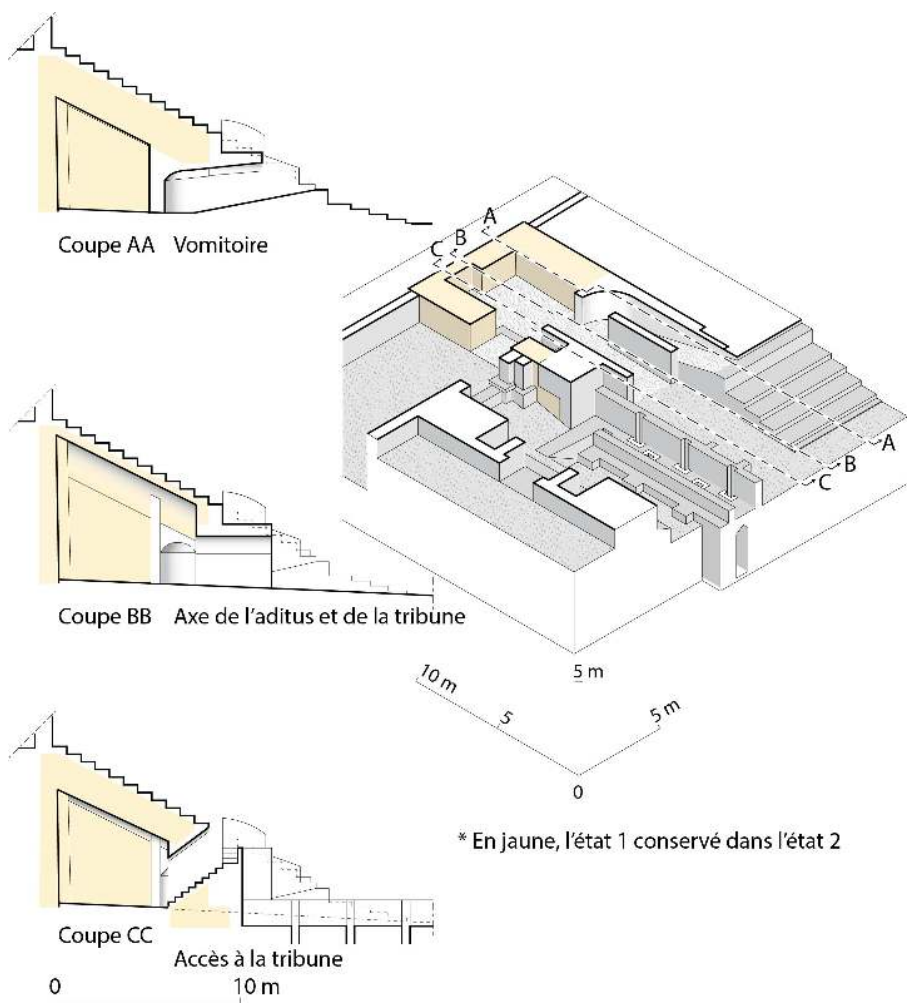

(C) IRAA/EFR. Relevés et dessin M. Fincker.

En empruntant le parcours en L légèrement courbe du vomitoire de l'ima cavea, on accède par une rampe montante à la précinction qui sépare la proédrie de l'ima cavea. Le sol du vomitoire, constitué d'un mortier à inclusions de fragments de marbre blanc, est partiellement conservé jusqu'au débouché. En amont, la rampe suit une pente beaucoup plus forte et elle est couverte par le sol moderne installé pendant les restaurations de $2010^{19}$. Les parois et la voûte surbaissée du vomitoire étaient enduites jusqu'au débouché.

La façade de ce dernier, en retrait de $20 \mathrm{~cm}$ par rapport à celle du débouché de l'aditus dans l'orchestra (fig. 16), était probablement plaquée de marbre, au moins en partie basse. On observe en effet un démaigrissement de la paroi en terre cuite du montant sud du débouché, correspondant à au moins un trou muni d'une cale en pierre pour une patte métallique destinée à maintenir le revêtement en marbre (fig. 17). 
Fig. 16 - Façades du débouché de l'aditus occidental du grand théâtre de Pompéi dans l'orchestra (au centre) et du débouché du vomitoire de l'ima cavea (à droite).

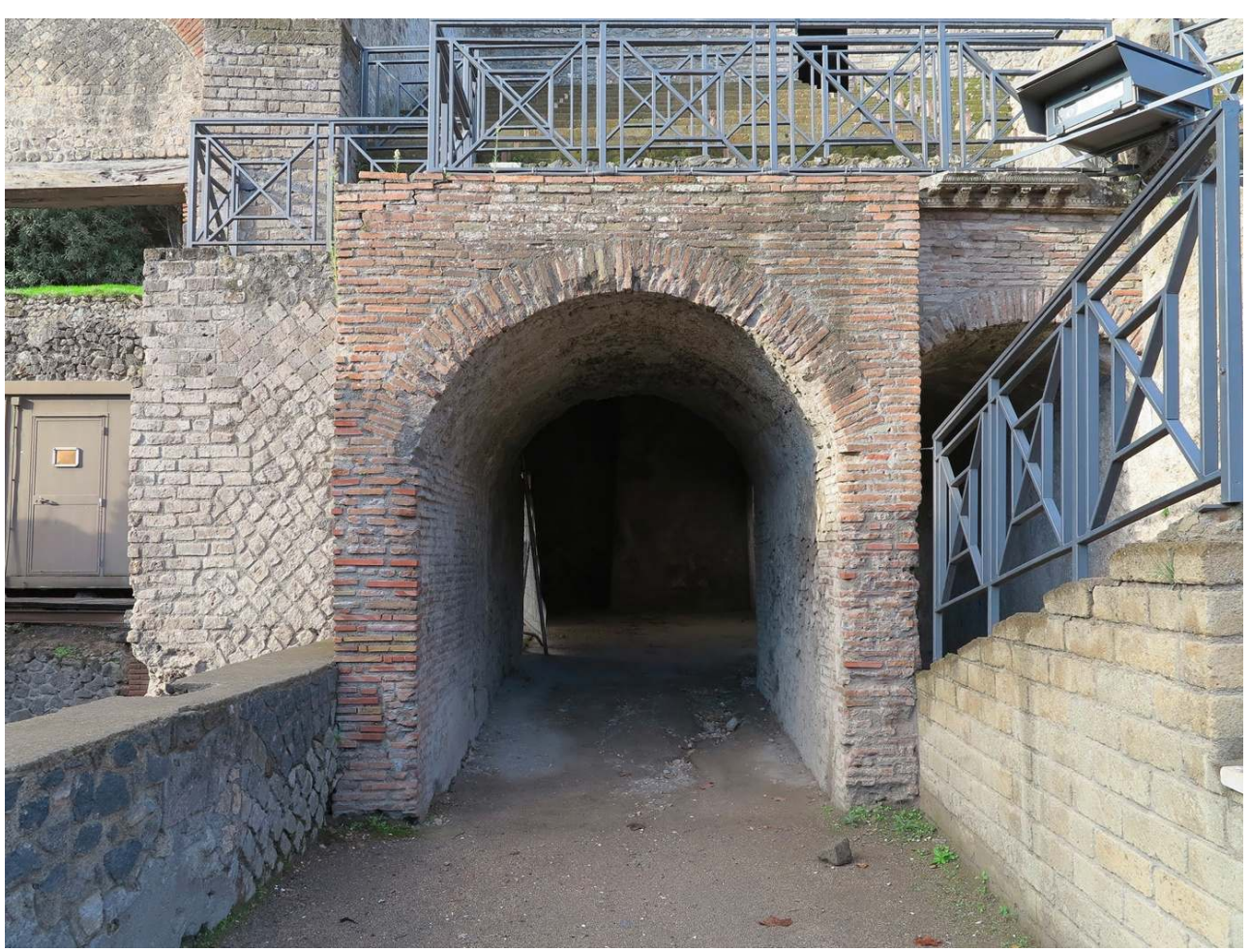

Cl. EFR/IRAA. Avec l'aimable autorisation de la Surintendance de Pompéi. 
Fig. 17 - Traces de l'accroche du placage en marbre au débouché du vomitoire de l'ima cavea (vue du nord).

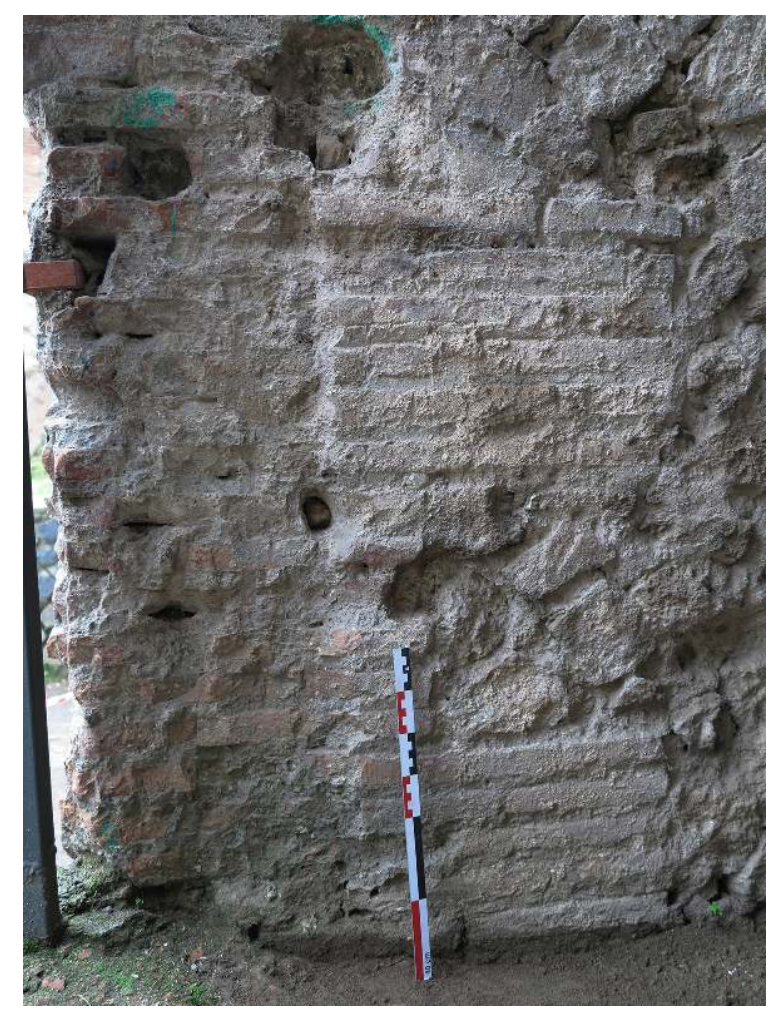

Cl. EFR/IRAA. Avec l'aimable autorisation de la Surintendance de Pompéi.

Le bloc de corniche corinthienne en marbre aujourd'hui placé au-dessus du débouché du vomitoire de l'ima cavea (fig. 16) a une longueur de $130 \mathrm{~cm}$; sa face de joint gauche, en biais à $45^{\circ}$ par rapport à la longueur, est en attente d'un bloc qui poursuivrait la corniche tout en formant un angle rentrant. La longueur du bloc tout comme l'attente d'un bloc formant retour à $90^{\circ}$ correspondent bien à la largeur du débouché $(136 \mathrm{~cm})$ et à sa configuration en retrait par rapport au débouché de l'aditus. Il n'a cependant pas été trouvé en place mais installé là à la fin $\mathrm{du}_{\mathrm{XIX}} \mathrm{e}^{\mathrm{e}}$., comme en témoigne notamment la photographie de G. Sommer ci-dessous datée entre 1870 et 1890, montrant le tribunal occidental, le débouché de l'aditus et le vomitoire de l'ima cavea avant la restauration de leurs parties hautes : la corniche est absente (fig. 18). 
Fig. 18 - Photographie du grand théâtre de Pompéi par Giorgio Sommer.

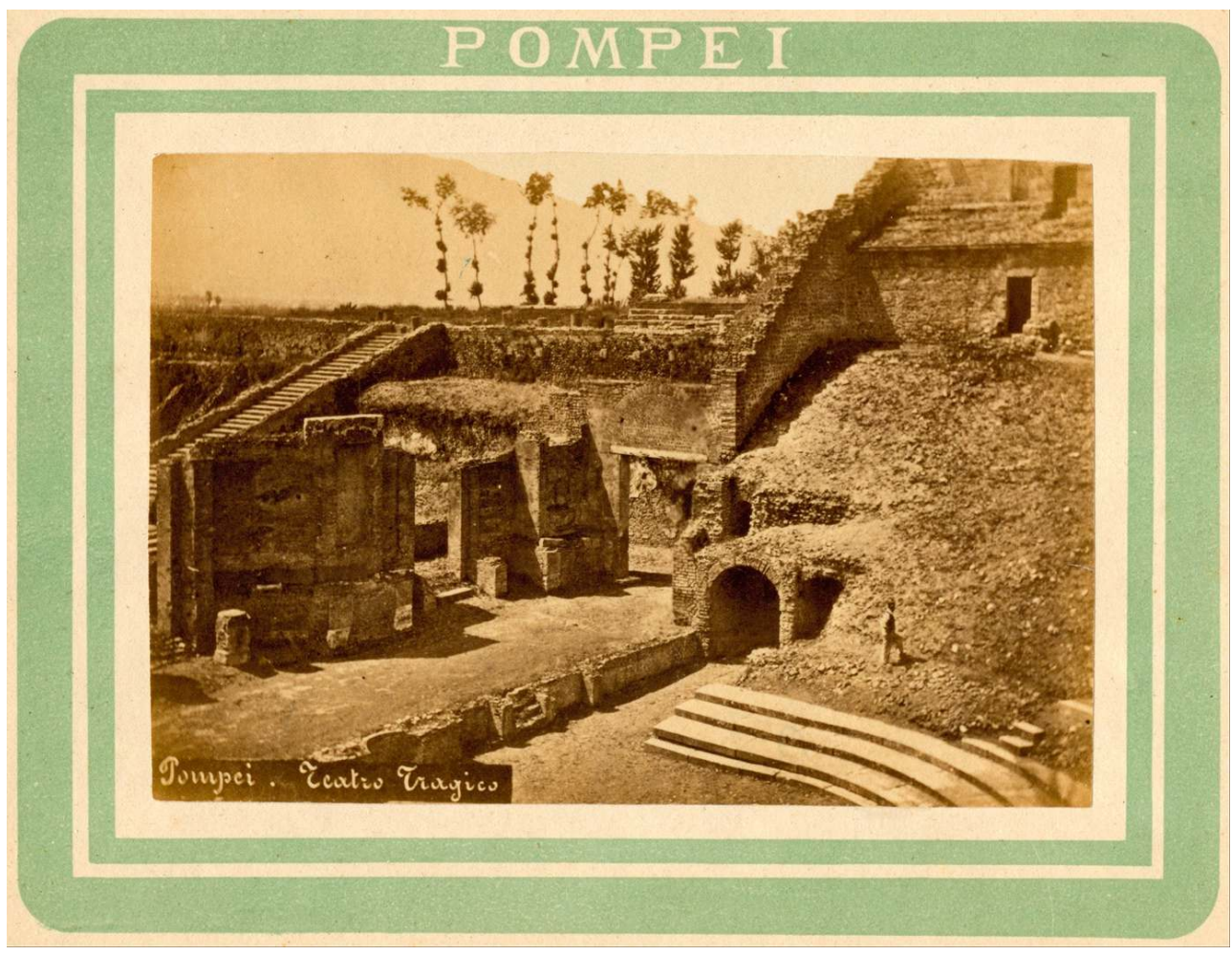

Source : Rijksmuseum, inv. RP-F-00-1786 (http://hdl.handle.net/10934/RM0001.COLLECT.242667)

30 Le débouché de l'aditus dans l'orchestra est couvert d'une voûte surbaissée maçonnée. La disparition de l'enduit laisse voir des traces du coffrage en bois sur lequel fut posée la maçonnerie de cette voûte. La façade du débouché de l'aditus, entièrement bâtie en terre cuite, était plaquée de marbre. Si les nombreuses restaurations modernes n'en ont laissé subsister que peu de traces de ce côté, on peut les observer plus clairement sur le débouché de l'aditus oriental.

31 Au-dessus de ce débouché se situe l'emplacement du tribunal (4,50 m N-S /2,40 m E-O) sur lequel pouvaient siéger quelques spectateurs privilégiés installés sur des sièges mobiles ( fig. 3). Dans le prolongement du montant oriental de la porte de l'entrée à l'aditus, on rencontre l'accès à cet espace réservé (fig. 12). Il s'agit, de bas en haut, d'un escalier de 10 marches en lave présentant des traces d'usure au centre jusqu'à un palier de changement de direction vers la gauche, puis de 3 marches dont deux maçonnées et une en marbre. L'escalier est couvert par une voûte rampante maçonnée qui s'interrompt à l'aplomb de la huitième marche, par un arc formé de claveaux de tuf. La partie haute de l'accès est à l'air libre. Comme on le voit sur la photographie de Giorgio Sommer (fig. 18), la tribune a subi de très lourdes restaurations modernes.

Dans l'alignement vertical de la deuxième marche de l'accès au tribunal, on observe deux trous percés dans l'enduit de chacun des deux murs de cet escalier. Également attestés à l'entrée de l'accès au tribunal oriental, ces encastrements pourraient correspondre à un dispositif de fermeture ou de restriction du passage. 


\section{Le theatrum tectum}

$C^{22}$. Les deux inscriptions, jumelles, ont été gravées sur un bloc en remploi. Il s'agit d'un ancien seuil monolithique à ailettes, en calcaire blanc très fin, soigneusement coupé en deux parties égales ${ }^{23}$. Les mortaises symétriques qui nous l'indiquent étaient certainement destinées, à l'origine, à la fixation d'un chambranle rapporté. Elles furent sans doute remplies d'un mortier dans lequel étaient tracées les parties manquantes des lettres qui apparaissent aujourd'hui coupées (fig. 19). Un tel remploi étonne dans le cadre d'une construction publique de cette envergure, pour laquelle on pourrait s'attendre à l'utilisation de blocs taillés ad hoc.

Fig. 19 - Montage photogrammétrique des deux inscriptions du theatrum tectum de Pompéi.

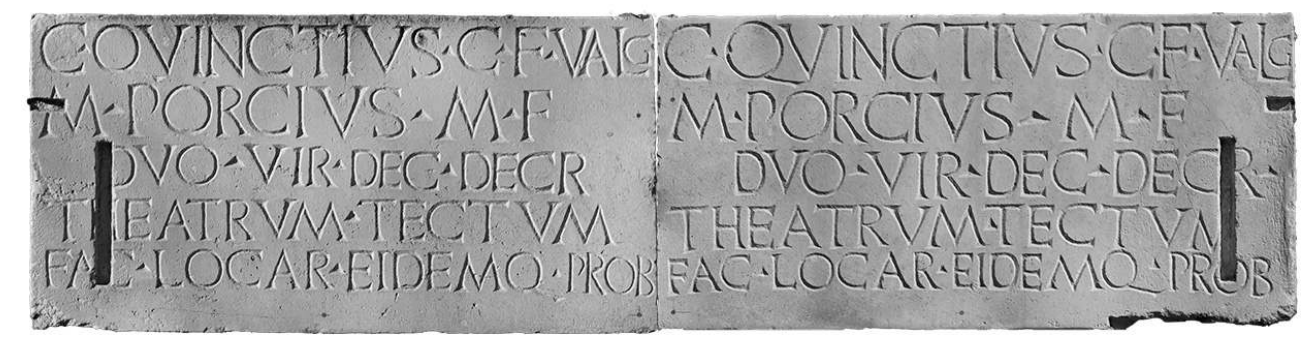

(c) IRAA/EFR, élaboration M. Fincker.

Les gradins de ce petit théâtre couvert sont inscrits dans une enceinte quadrangulaire d'environ $29 \times 30 \mathrm{~m}$, à laquelle s'ajoute un postscaenium de $29 \times 5 \mathrm{~m}$. La maçonnerie de l'enceinte quadrangulaire et du front de scène est constituée de petits moellons de lave relativement réguliers mis en œuvre de façon à former un appareil s'approchant du réticulé. Les chaînages d'angles et les piédroits des ouvertures sont réalisés en fragments de tuiles ${ }^{24}$ disposés "en dents de scie ${ }^{25}$. Les trous de boulins, alignés selon un rythme régulier, sont aménagés avec un moellon de calcaire.

On constate une assez forte différence de niveau $(1,15 \mathrm{~m})$ entre le sol de circulation à l'extérieur du théâtre et le dallage de l'orchestra; les deux aditus présentent une pente descendante vers cette dernière. En revanche, l'accès depuis l'extérieur vers le pulpitum - dont on peut restituer le niveau du plancher grâce aux encastrements de poutres conservés en partie basse du front de scène et dans la face sud de la tribune occidentale pouvait se faire de plain-pied par les portes latérales de la scène ${ }^{26}$; il en allait de même pour les accès latéraux au postscaenium. La rue qui longe le theatrum tectum au sud est en revanche située légèrement en contrebas.

L'espace réservé au public se divise en trois zones : deux tribunes latérales situées audessus des aditus et séparées du reste des gradins par les murs de soutènement de la cavea 
(K sur la fig. 20) ; quatre rangs de degrés bas en lave destinés à recevoir les sièges mobiles de la proédrie $(\mathrm{F})$ - isolée par une précinction délimitée par une balustrade en tuf -, et enfin 18 rangs de gradins de la cavea, en maçonnerie (très restaurée) surmontée de blocs moulurés de tuf, divisés en 5 cunei par des escaliers en lave (E).

Fig. 20 - Plan du theatrum tectum de Pompéi d'après Fr. Mazois (Les ruines de Pompéi IV, 1838, pl. 28) ; le nord est conventionnellement placé en haut de l'image.

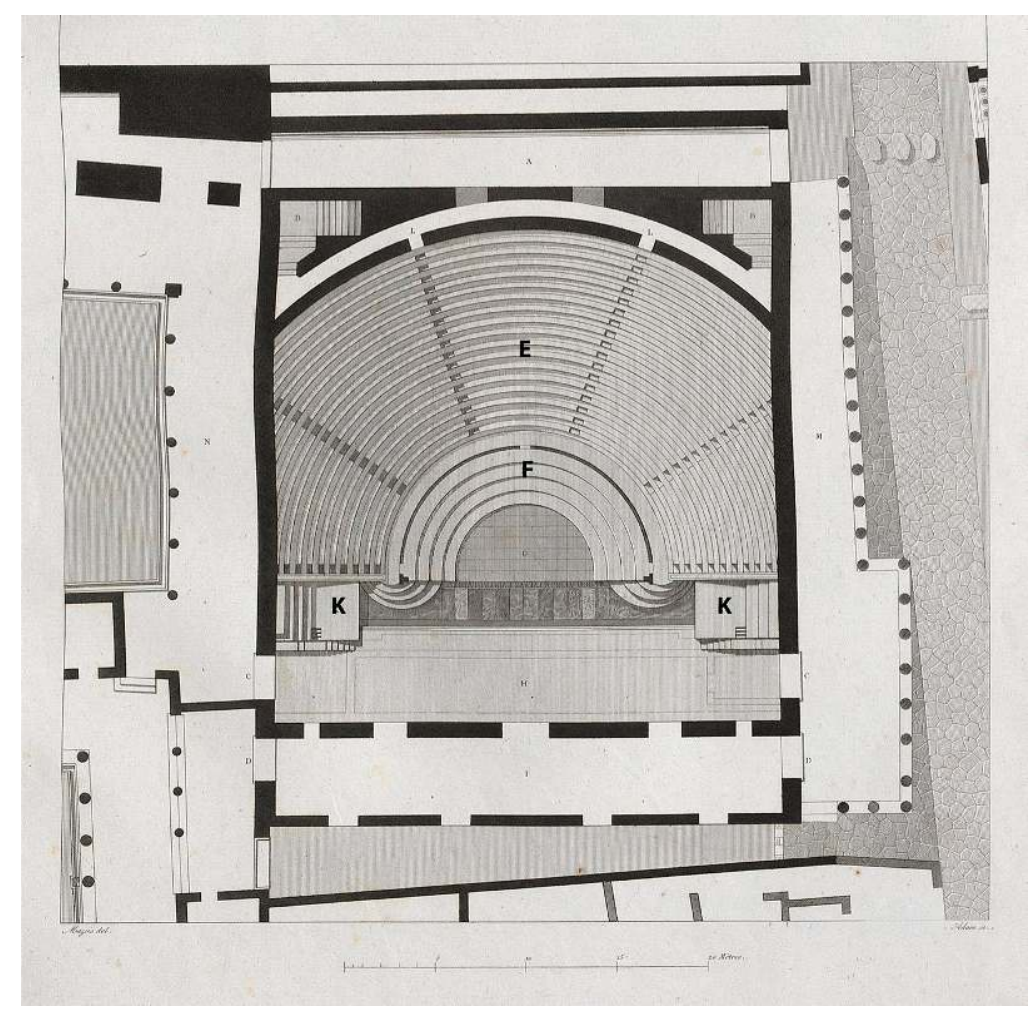

On pouvait accéder aux parties hautes des gradins par l'arrière du bâtiment, à travers deux cages d'escaliers ménagées dans les angles de l'enceinte quadrangulaire, accessibles par des portes donnant sur le couloir VIII 7, 20. Le public pouvait également entrer par les deux aditus dans l'orchestra et se rendre directement à la proédrie, ou bien, en gravissant les quatre marches qui menaient à la précinction, dans les parties basses de la cavea. Les spectateurs qui siégeaient sur les tribunes latérales devaient quant à eux passer sur le pulpitum pour pouvoir emprunter le petit escalier adossé à la tribune, côté scène ${ }^{27}$.

Tous les accès à ce théâtre (portes arrière, portes des aditus, portes latérales du bâtiment de scène, portes du postscaenium) ainsi que les deux extrémités du couloir VIII 7, 20 pouvaient être clos, comme en témoignent les aménagements des seuils et des montants conservés. On peut y voir un indice en faveur de l'utilisation de ce théâtre pour certaines réunions « réservées $»^{28}$.

Pendant cette première campagne d'étude, nos observations se sont concentrées sur les aditus et les tribunes latérales, plus particulièrement dans la moitié occidentale de l'édifice ${ }^{29}$. Contrairement au grand théâtre, on ne peut observer pour ces éléments plusieurs phases de construction dans les élévations conservées : nous donnons donc une description synchronique de l'état actuel. En revanche, nous exposons par la suite une série d'observations qui nous laissent penser que le theatrum tectum a tout de même pu 
subir certaines transformations ou remaniements, qui feront l'objet de recherches ultérieures.

\section{L'aditus occidental}

41 L'entrée dans l'aditus occidental du theatrum tectum s'effectuait, depuis le portique en L situé entre les deux théâtres, par une porte de 2,33 m de large ouverte dans la façade occidentale à côté des portes latérales de la scène et du postscaenium (fig. 21). Cette façade était revêtue d'un enduit peint de couleur rouge, au moins en partie basse. Quelques vestiges en ont été conservés sous le mur appuyé perpendiculairement à la façade du theatrum tectum, entre la porte latérale de la scène et celle du postscaenium, dans une phase tardive.

Fig. 21 - Entrée de l'aditus occidental (à gauche) et entrée latérale de la scène (à droite) du theatrum tectum de Pompéi.

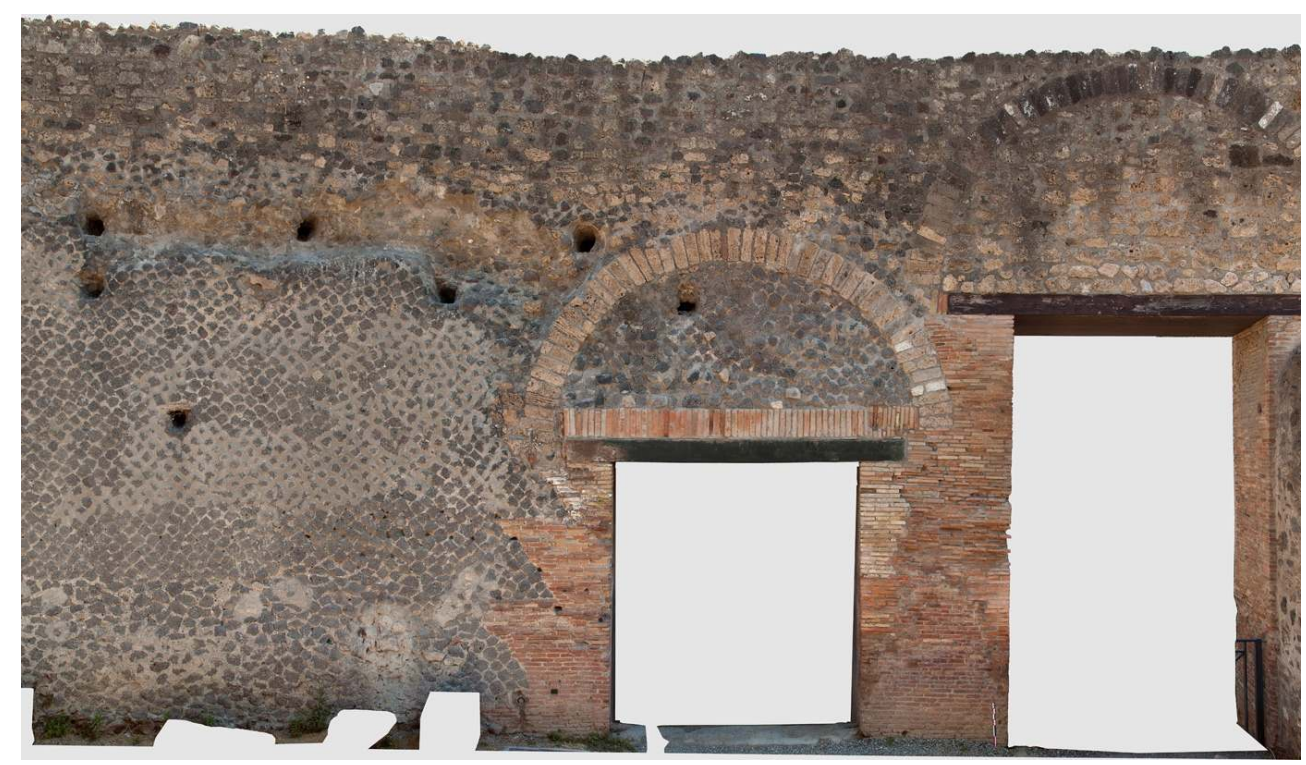

Cl. et assemblage préliminaire: Th. Crognier, EFR/IRAA. Avec l'aimable autorisation de la Surintendance de Pompéi.

Les piédroits de la porte de l'aditus sont réalisés en maçonnerie de tuiles, le linteau et la platebande qui reposent dessus sont issus de restaurations modernes. Comme toutes les ouvertures de l'édifice, cette porte est surmontée par un arc de décharge en claveaux de calcaire du Sarno. Le seuil, composé de deux blocs de lave, présente une feuillure et deux mortaises carrées qui ont pu servir de logement pour des crapaudines ; l'ensemble permet de restituer une porte à double battant s'ouvrant vers l'intérieur de l'édifice. Certaines des mortaises visibles sur le seuil pourraient aussi être liées à l'installation de grilles modernes destinées, depuis 1794 jusqu'à la fin du XIX ${ }^{\mathrm{e}}$ s., à contrôler tous les accès au bâtiment (fig. 22). 
Fig. 22 - Vue de l'aditus occidental du theatrum tectum depuis le débouché de l'aditus oriental par F.-C. Gau, dans Fr. Mazois et al., Les ruines de Pompéi IV, 1838, pl. 27.

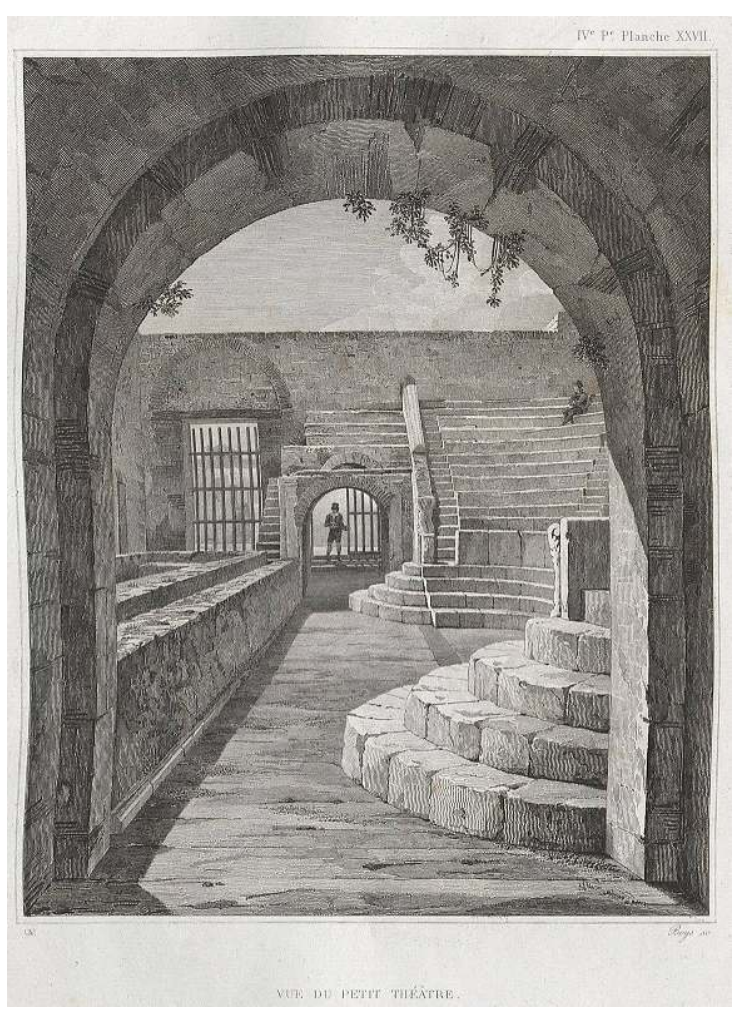

SOURCE : gALLICA.BNF.FR / BNF.

Pour décrire l'aditus nous distinguerons trois parties qui présentent chacune une couverture différente : l'escalier (1), la partie centrale (2) et le débouché dans l'orchestra (3) (fig. 23). 
Fig. 23 - Coupe Ouest-Est sur l'aditus occidental du theatrum tectum de Pompéi.

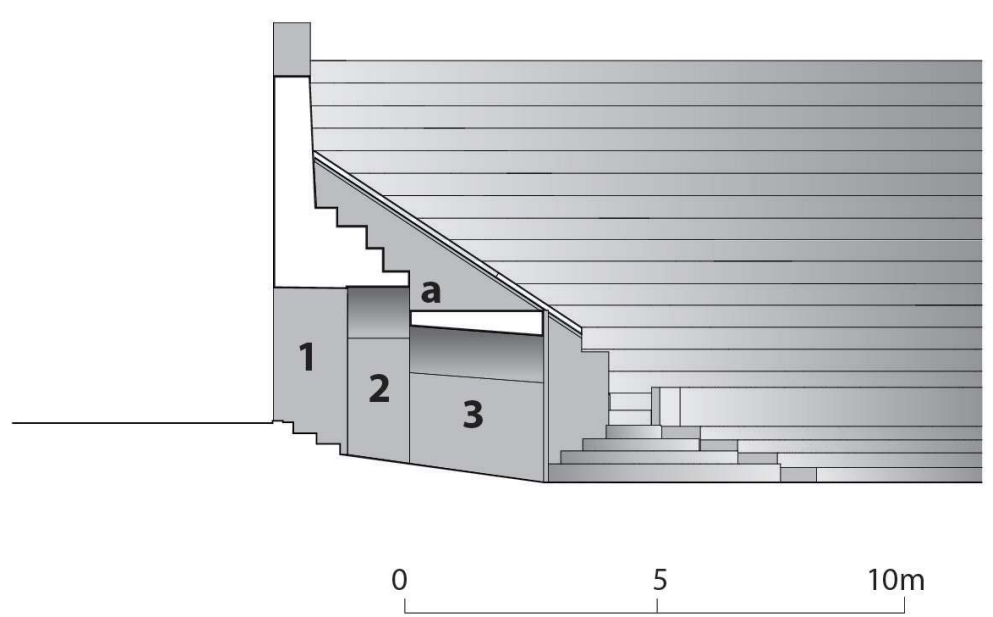

\section{(C) IRAA/EFR. Relevé et dessins S. Zugmeyer.} forme un berceau régulier. Dans le débouché dans l'orchestra (3), c'est une voûte en berceau rampante qui assure le couvrement. Celle-ci est sensiblement plus basse que la précédente si bien que le contact entre ces deux voûtes forme un décrochement de $76 \mathrm{~cm}$; un jour (a) est ainsi créé entre l'intrados de la voûte de la partie centrale (2) et l'extrados de la voûte rampante qui surmonte le débouché dans l'orchestra (3) et supporte le sol de la partie antérieure de la tribune (fig. 23-24). On peut se demander si ce jour existait dans l'Antiquité ou si une cloison venait le clore. 
Fig. 24 - Vue de l'aditus occidental du theatrum tectum depuis l'entrée ; détail de l'arc de tête de la voûte rampante du débouché.

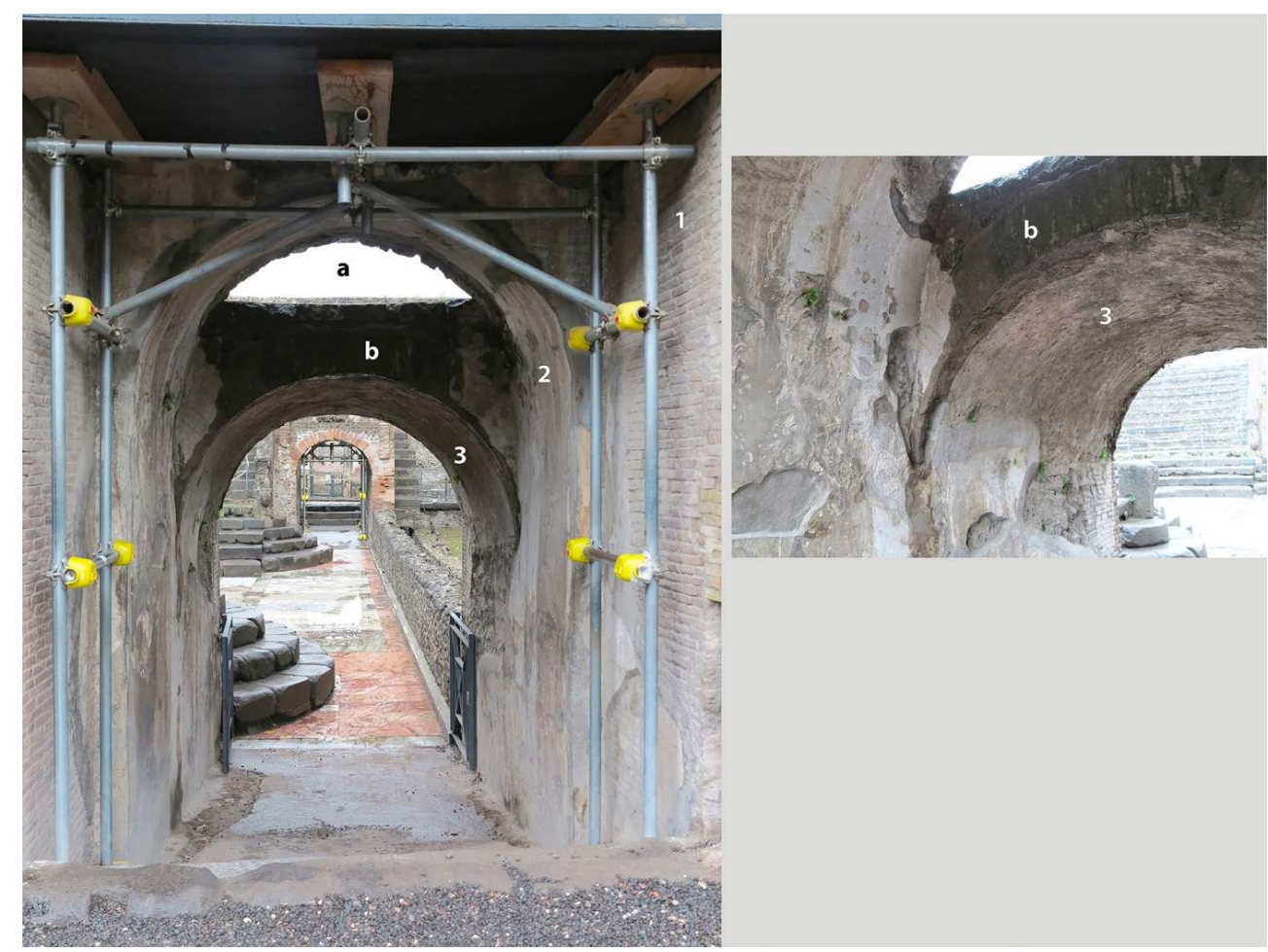

Cl. EFR/IRAA. Avec l'aimable autorisation de la Surintendance de Pompéi.

47 L'arc de tête de la voûte rampante dans le couloir de l'aditus, constitué de claveaux de calcaire et de tuf semble d'origine (b sur la fig. 24). En revanche, l'arc de tête de la voûte en berceau de la partie centrale (2) visible depuis l'orchestra est une restauration moderne faite suivant la même technique. En effet, sur une photographie de G. Sommer (fig. 25), datable autour de 1870 , on peut voir que cet arc avait disparu. 
Fig. 25 - Photographie du theatrum tectum depuis le débouché de l'aditus oriental par Giorgio Sommer.

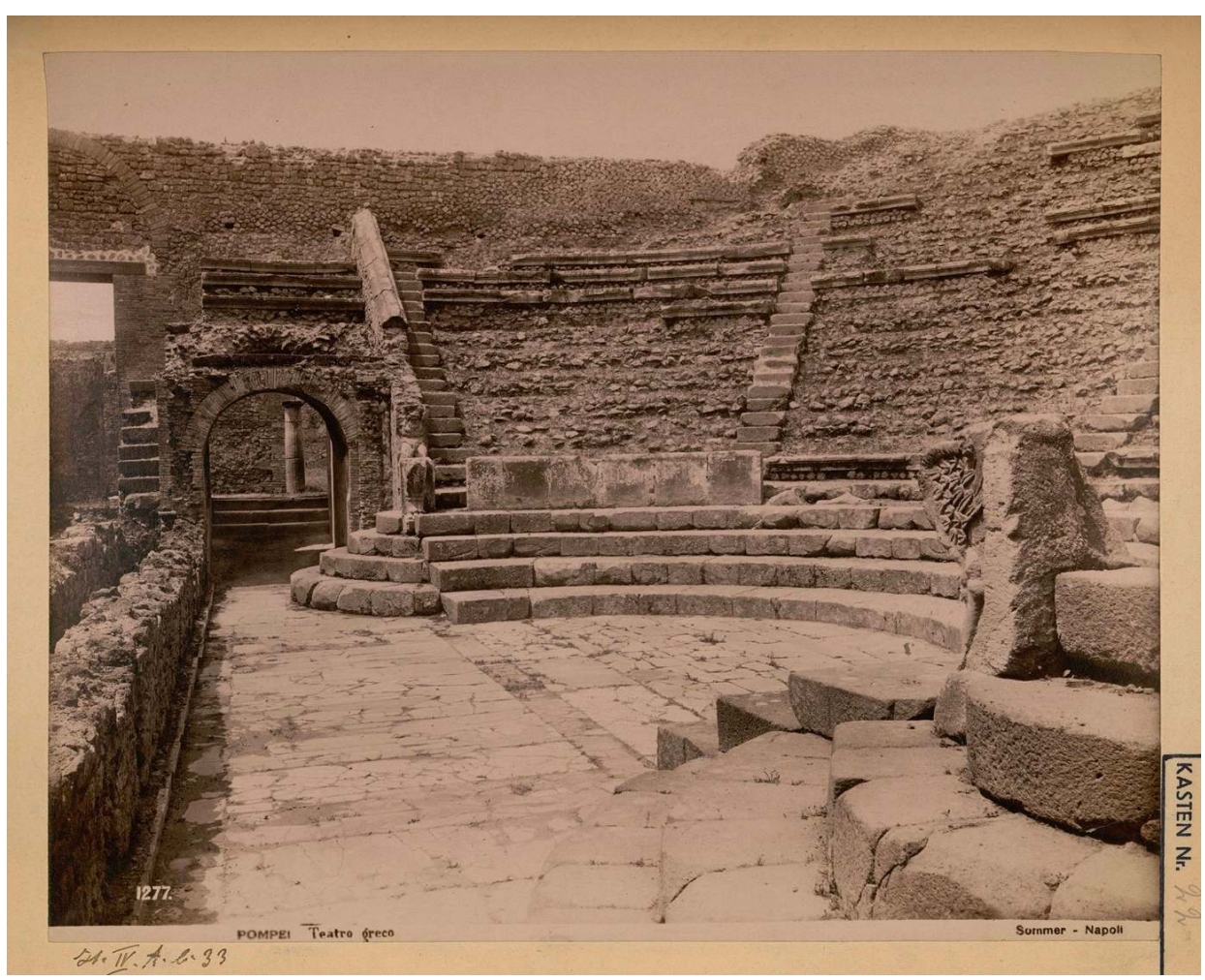

Coll. Bibliothèque de la Maison Interuniversitaire des Sciences de l'Homme, Alsace (http:// docnum.unistra.fr/cdm/ref/collection/coll4/id/961)

Les parements des murs latéraux de l'aditus sont bâtis entièrement en terre cuite dans la partie la plus large, au niveau de l'escalier (fig. 23 et $\mathbf{2 4}, 1$ ) puis en maçonnerie avec chaînages à harpes en terre cuite dans la partie centrale et le débouché. Les murs latéraux et les voûtes étaient recouverts du même enduit blanc, particulièrement bien conservé dans la partie centrale ${ }^{30}$, ce qui empêche d'observer la continuité de la maçonnerie. Cependant dans l'aditus oriental, où l'enduit est moins bien conservé, on constate une assez grande homogénéité de la construction de l'ensemble de la structure.

La face du débouché donnant sur l'orchestra, entièrement en terre cuite si on excepte les restaurations modernes ${ }^{31}$, est relativement bien conservée dans l'aditus occidental ${ }^{32}$. Il s'agit d'un arc encadré de pilastres, dont on ne connaît pas le couronnement antique. Quelques trous munis de cales en pierre pour des pattes métalliques permettent d'assurer que l'arc ainsi que les pilastres étaient revêtus d'un décor plaqué en marbre, tandis que les parties latérales, à l'extérieur des pilastres, étaient, elles, revêtues d'un enduit peint dont quelques vestiges sont conservés, à l'angle avec le mur de soutènement des gradins. Ce dernier est composé d'un appareil de moellons de lave assez proche de celui des façades, il était également enduit.

50 La largeur du passage vers l'orchestra était réduite par la présence d'une série de marches en lave donnant accès à la précinction (fig. 25-26). Ces marches, disposées en 4 rangs et adossées au mur de soutènement des gradins ainsi qu'aux trois degrés supérieurs de la proédrie, forment un dispositif assez rare, qu'on ne retrouve que dans les théâtres tardorépublicains de Pietrabbondante et Sarno. Les blocs de lave qui les composent ne sont pas 
disposés en demi-cercles concentriques mais forment des courbes irrégulières permettant une continuité des marches avec les 3 gradins les plus hauts de la proédrie.

Fig. 26 - Orthophotographie par drone de l'orchestra du theatrum tectum de Pompéi.

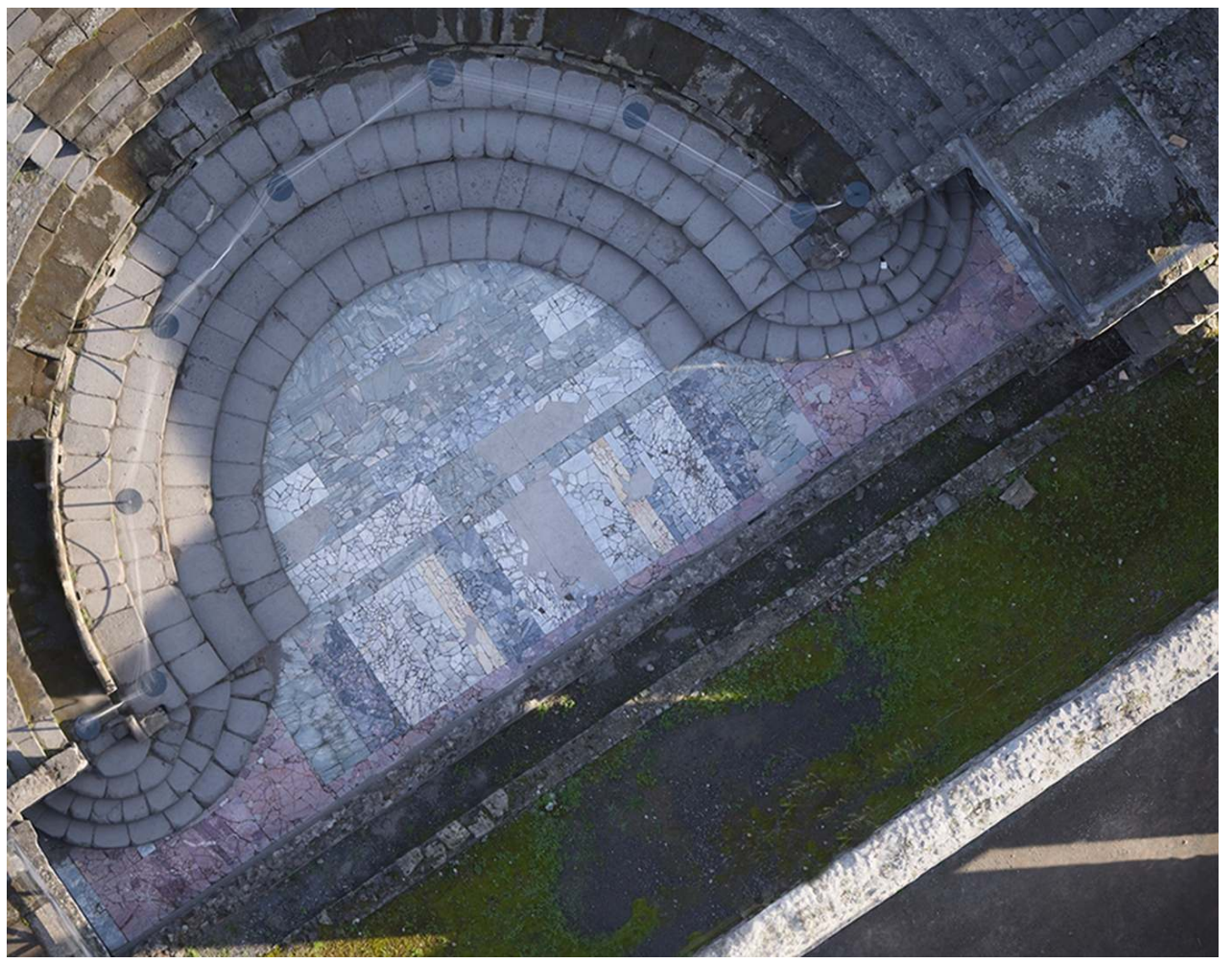

Cl. Soprintendenza Pompei. Avec l'aimable autorisation de la Surintendance de Pompéi.

\section{La tribune latérale occidentale}

51 La tribune latérale se compose de deux parties: trois rangs de gradins installés sur les voûtes couvrant l'escalier (1) et la partie centrale (2) de l'aditus et, en contrebas, une plateforme aménagée sur l'extrados de la voûte du débouché de l'aditus dans l'orchestra (3) (fig. 27).

Les gradins sont construits comme ceux du reste de la cavea, en maçonnerie surmontée de blocs moulurés de tuf. Sur la plateforme, dont le pavement est formé par un dallage de tuf ${ }^{33}$, on pouvait placer quelques sièges mobiles honorifiques. Un garde-corps probablement en bois fermait la plateforme du côté de l'orchestra et de la scène. Les 3 poteaux de section carrée $(6 \times 6 \mathrm{~cm})$ qui le soutenaient étaient encastrés dans des mortaises encore visibles dans le dallage. 
Fig. 27 - Modèle axonométrique schématique de l'aditus et de la tribune ouest du theatrum tectum de Pompéi.

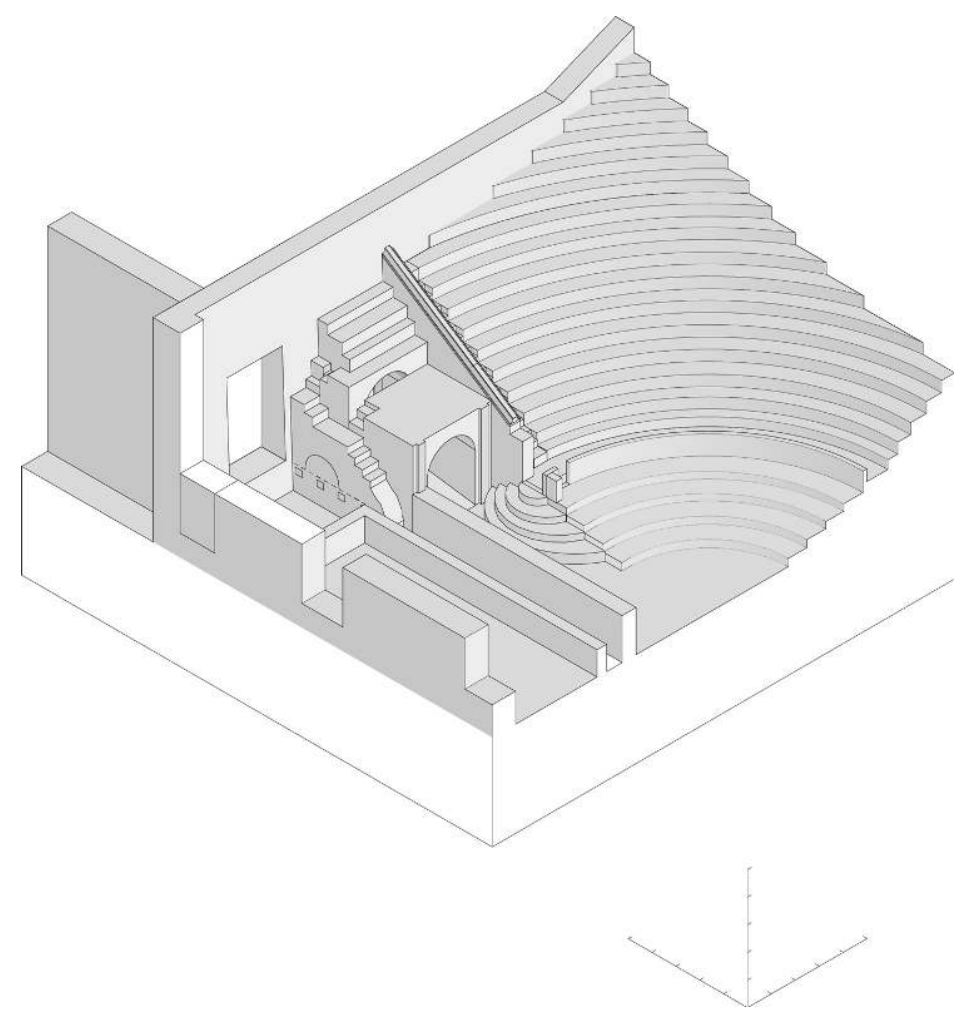

(c) IRAA/EFR. Relevé et dessin S. Zugmeyer.

53 L'accès aux gradins comme à la plateforme se faisait par un escalier étroit accessible depuis le pulpitum (fig. 27-28). La maçonnerie de sa structure est constituée de moellons de lave et de calcaire, les marches sont, elles, formées de blocs de lave. Il présente une première volée de marches conduisant à un palier (c), donnant accès à droite à la plateforme (d) et tout droit à un escalier demi-tournant et palier (e) menant devant le gradin inférieur de la tribune.

La deuxième volée de cet escalier est ménagée directement dans la maçonnerie située audessus des voûtes. Un problème de conception a obligé les constructeurs à réaliser un petit massif maçonné(f) d'une cinquantaine de centimètre de haut, au-dessus du palier (e), contre le couvrement de l'aditus sans quoi un jour se serait formé entre ce palier et l'aditus. Ce massif rend le passage encore plus étroit et l'accès aux gradins peu aisé. 
Fig. 28 - Vue de l'accès à la tribune latérale occidentale du theatrum tectum depuis la scène.

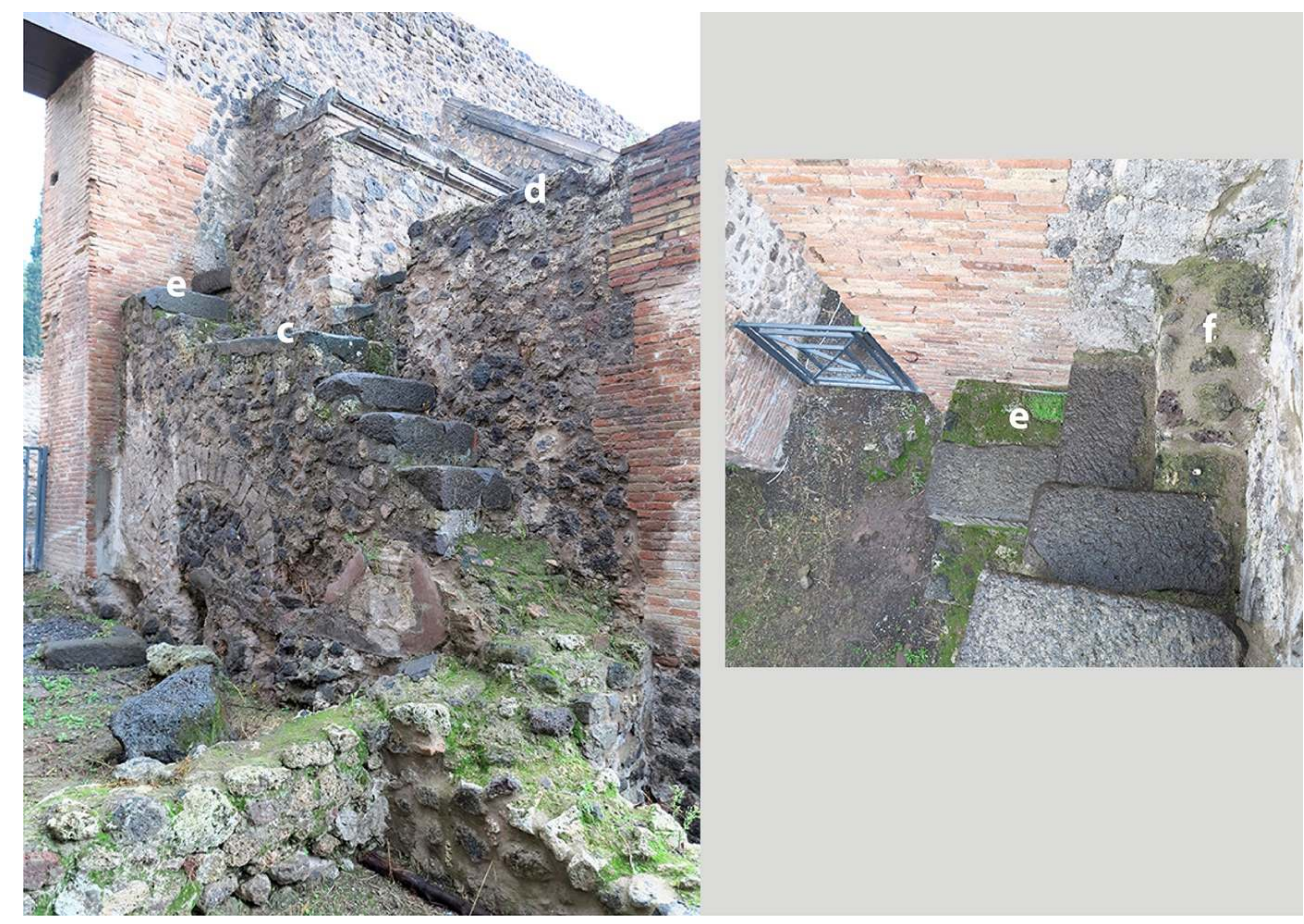

(c) EFR/IRAA. Avec l'aimable autorisation de la Surintendance de Pompéi.

Contrairement à ce qu'on observe au grand théâtre, les gradins qui surplombent la plateforme de la tribune étaient isolés, comme elle, du reste de la cavea par le mur de soutènement en maçonnerie de lave. Ce mur rampant est couronné d'un chaperon mouluré en tuf qui suit une pente oblique parallèle à celle des gradins. Seule la partie supérieure du mur et des chaperons est conservée (fig. 26, 28). Un bloc de tuf sculpté en forme d'atlante agenouillé décorait l'extrémité inférieure de ce mur. Cet élément de décor appartient, pour des raisons stylistiques et typologiques, à une série d'éléments problématiques concernant la chronologie du theatrum tectum.

\section{Le theatrum tectum, une construction homogène ou remaniée?}

Les deux inscriptions placées sur les façades du monument permettent de situer le chantier concerné dans les années 80 à $70 \mathrm{av}$. J.-C. En raison de la présence de cette dédicace et de l'homogénéité apparente des techniques de construction, ce théâtre a généralement été considéré comme une construction homogène, qui n'aurait pas connu de remaniements. Cependant, plusieurs indices nous conduisent aujourd'hui à nuancer cette affirmation. L'utilisation de modèles architecturaux et décoratifs attestés dans des édifices de date nettement antérieure, comme les théâtres de Sarno et Pietrabbondante, associés à des indices visibles dans la construction de la proédrie et des escaliers des aditus, nous font aujourd'hui penser que le theatrum tectum a pu subir lui aussi des remaniements ou tout au moins bénéficier de remplois architecturaux. 


\section{Le décor sculpté en tuf}

57 Plusieurs éléments suggèrent que le décor sculpté en tuf de la cavea - les atlantes agenouillés placés en bas du mur de soutènement des gradins et les pattes de griffons situées aux extrémités de la balustrade de la précinction (fig. 29) -ne se trouvent pas dans leur situation initiale.

Fig. 29 - Vue générale du décor sculpté du theatrum tectum, à l'extrémité occidentale des gradins.

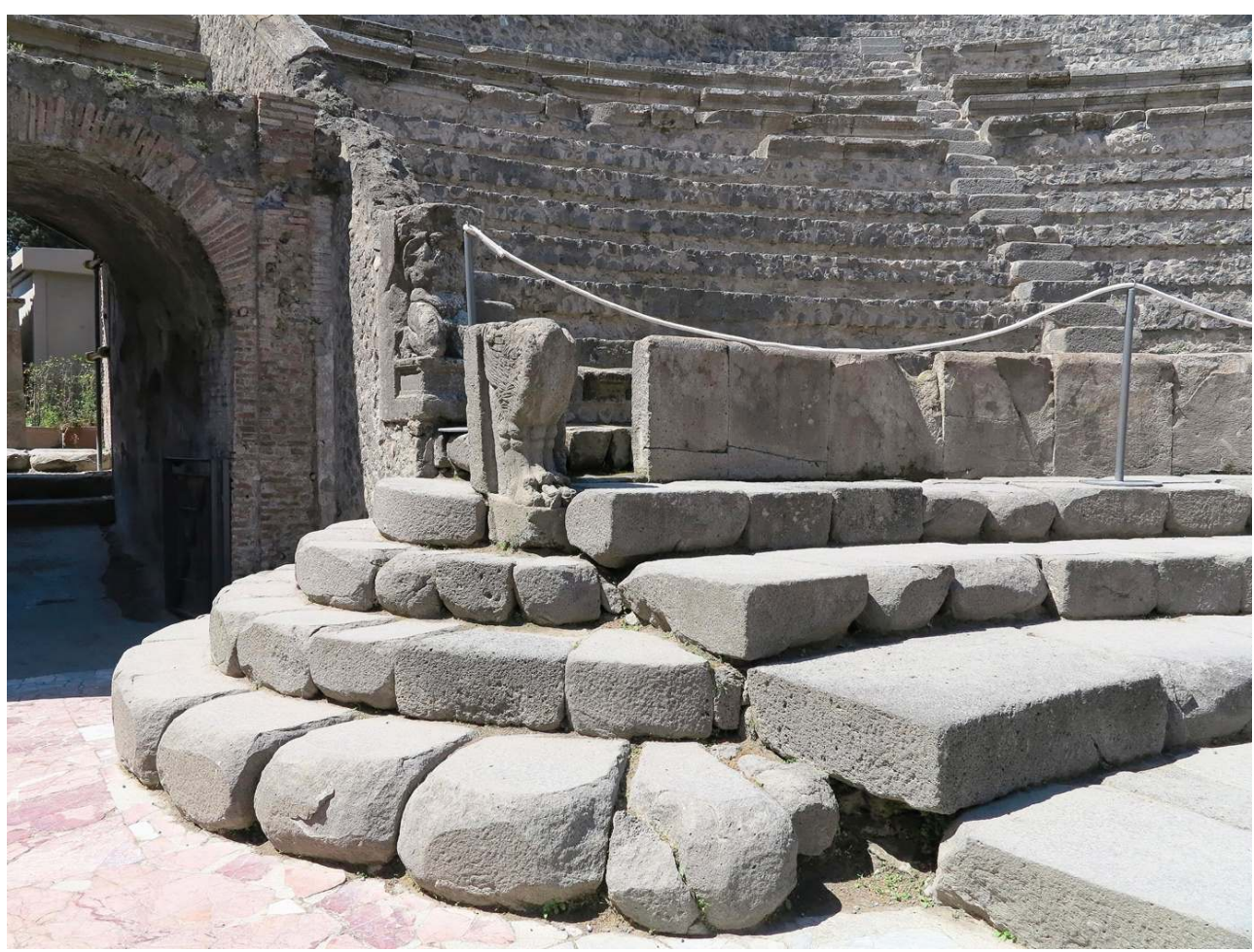

CI. EFR/IRAA. Avec l'aimable autorisation de la Surintendance de Pompéi.

Les blocs de tuf avec les atlantes sculptés, sont extrêmement bien conservés. D'une hauteur d'assise de $120 \mathrm{~cm}$ pour une largeur de $42 \mathrm{~cm}$, ils forment la tête des deux murs de soutènement des gradins au niveau de la précinction. Cependant, leur position actuelle est une restauration de la fin du XVIII ${ }^{\mathrm{e}}$ siècle. Les journaux de fouilles indiquent en effet, qu'ils ont été trouvés sur le sol ${ }^{34}$. Sur leur face de parement, côté cavea, on note un démaigrissement de la surface indiquant l'emplacement de deux marches de l'escalier qui les bordait (fig. 30). Or le profil des marches actuelles ne suit pas les traces laissées dans le bloc. Cela correspond-il une légère erreur des restaurateurs, ou bien s'agit-il de la trace d'une mise en œuvre antérieure? 
Fig. 30 - Face nord du bloc sculpté représentant un atlante agenouillé visible sur la figure précédente. Le démaigrissement est surligné en rouge.

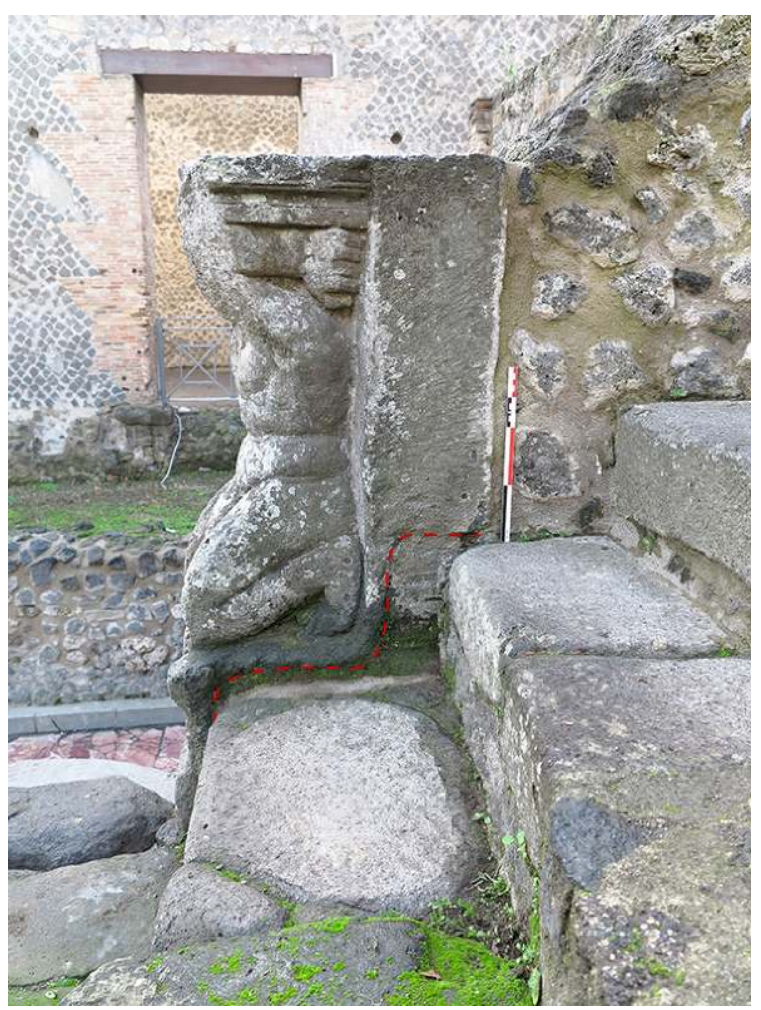

Cl. EFR/IRAA Avec l'aimable autorisation de la Surintendance de Pompéi.

59 Plus étonnant : à l'ouest, le bloc de balteus orné d'une patte de griffon placé à l'extrémité du degré supérieur de la proédrie est encastré grossièrement. L'assise du gradin est plus haute que la sculpture, si bien que le décor se trouve en partie caché (fig. 31). La mise en œuvre apparaît maladroite, au regard de la qualité du décor : il pourrait donc se trouver en situation de remploi ou avoir subi une adaptation ou un déplacement au sein du monument. 
Fig. 31 - Encastrement de la patte de griffon dans la dernière marche du rang supérieur de la proédrie (côté occidental).

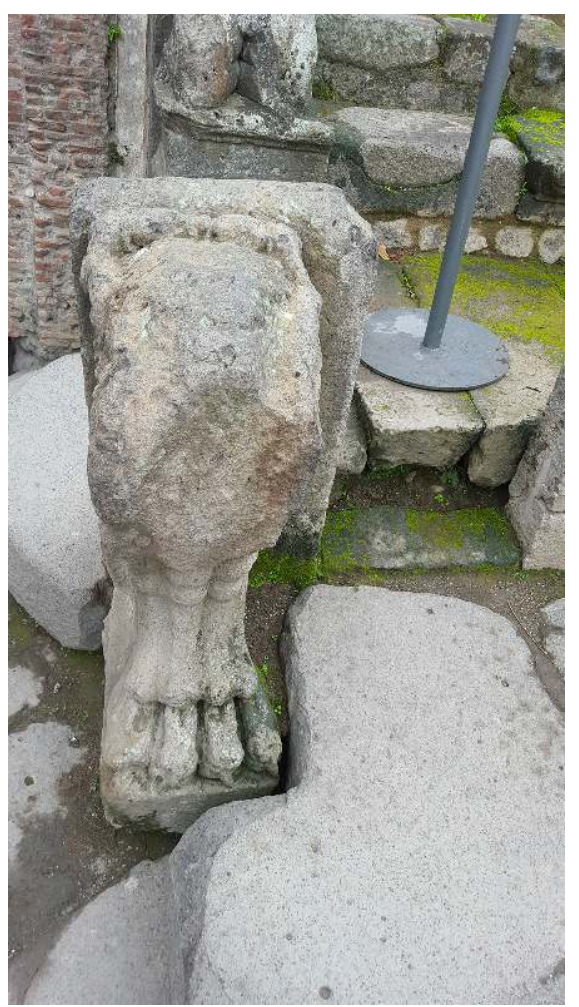

Cl. EFR/IRAA. Avec l'aimable autorisation de la Surintendance de Pompéi.

\section{La proédrie}

personnes de haut rang, distingue le dispositif de Pompéi de ceux - très voisins - de Pietrabbondante et Sarno dotés, eux, de gradins à dossiers. Elle présente, elle aussi, plusieurs éléments qui suggèrent qu'elle a subi des remaniements.

61 Tout d'abord, on distingue deux types de mise en œuvre dans les blocs de lave des gradins bas de la proédrie. La plupart d'entre eux sont posés de façon régulière, les blocs sont de tailles équivalentes et l'orientation des joints est à peu près concentrique vers le centre de l'orchestra. Cependant, quelques blocs situés pour la plupart sur le deuxième gradin sont appareillés différemment; les dimensions de ces blocs sont variables et les joints ne sont pas orientés vers le centre de l'orchestra; certains blocs sont étroits avec des joints presque parallèles et d'autres, au contraire, qui sont plus larges avec des joints convergents, adoptent la forme d'une clé de voûte horizontale (voir fig. 26). En outre, on note que ces deux modes de mise en œuvre correspondent à l'utilisation de deux types de lave différents. Il pourrait s'agir d'une réparation de la proédrie, cependant l'analyse de ces éléments doit encore faire l'objet d'un relevé spécifique.

Enfin, sur les faces verticales visibles des blocs de gradin situés aux extrémités de la proédrie (rang 3 en partant du bas à l'ouest, rangs 1 et 3 à l'est), on observe des traces d'encastrements qui ne correspondent pas à leur disposition actuelle (fig. 32). La position des marches concentriques adossées aurait-elle été modifiée? Une telle transformation pourrait-elle expliquer l'irrégularité de leur plan? On note d'ailleurs que certaines 
marches de ces escaliers sont taillées dans le même type de lave que celui des réparations supposées de la proédrie.

Fig. 32 - Lien des marches et des degrés bas de la proédrie dans la partie orientale de la cavea, les flèches rouges indiquent les traces d'encastrements suggérant un remaniement.

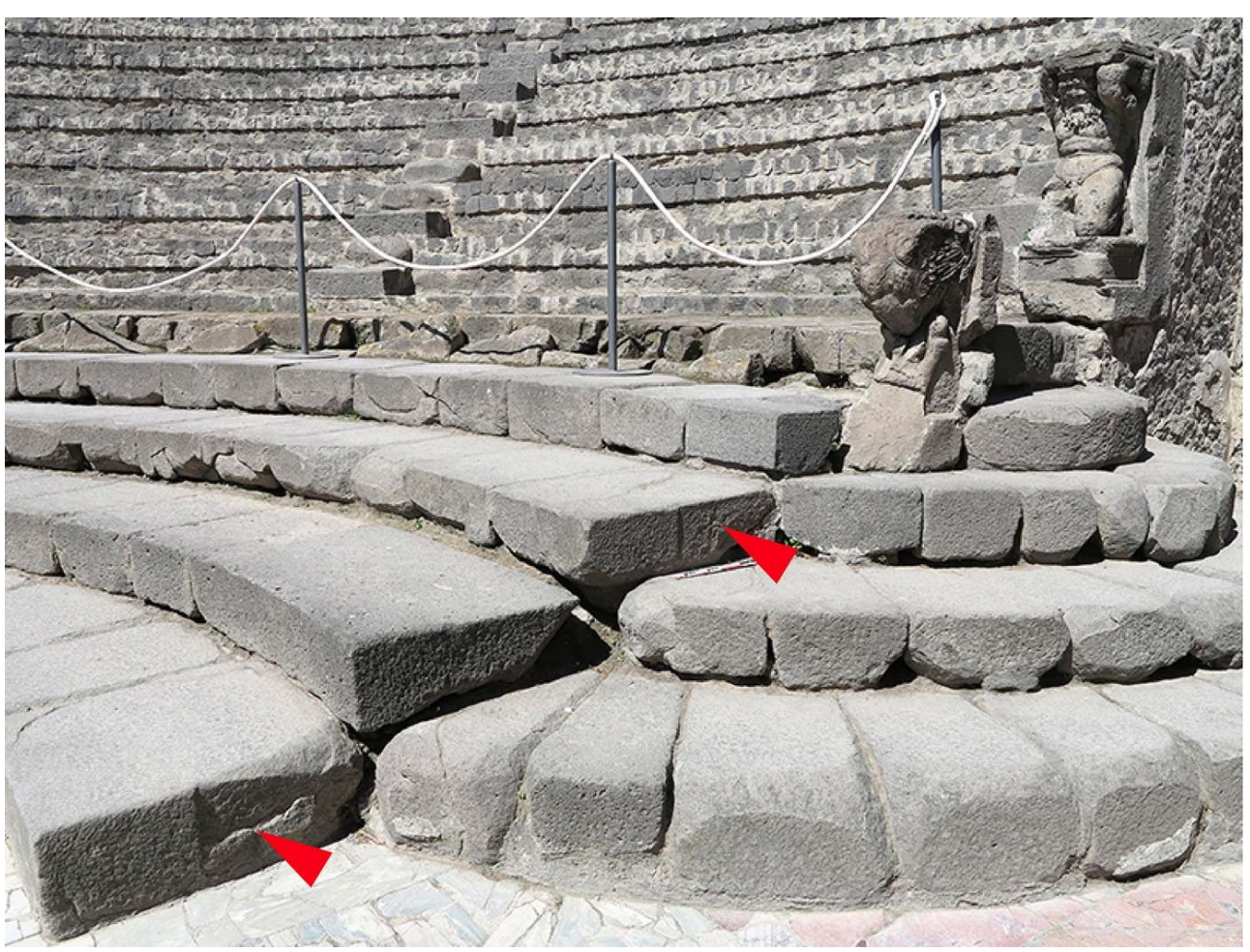

Cl. EFR/IRAA. Avec l'aimable autorisation de la Surintendance de Pompéi.

\section{Le dallage de l'orchestra}

Un cas de remaniement assuré réside dans l'installation du dallage en marbre polychrome de l'orchestra. Une inscription en lettres de bronze - trouvée en place au moment des fouilles ${ }^{35}$ endommagée ${ }^{36}$ et restaurée de manière erronée ${ }^{37}$, elle n'est plus visible aujourd'hui - indiquait en effet que ce dallage avait été financé par un magistrat de la colonie, à la place d'une subvention pour des jeux :

M(arcus) Oculatius M(arci) f(ilius) Verus II vir pro ludis ${ }^{38}$.

La date de cette intervention est difficile à situer précisément, mais elle est forcément postérieure à la construction de l'enceinte du monument ${ }^{39}$.

\section{Les portes d'accès à l'arrière de la cavea}

Enfin, la dernière transformation assurée dans le theatrum tectum consista dans la reconstruction, en appareil mixte de tuf et de terre cuite, des piédroits des portes donnant accès à la cavea par l'arrière, depuis le couloir VIII 7, 20. La construction de ces montants resserra la largeur des deux baies, oblitérant par la même occasion les blocs de seuil en lave de la phase précédente (fig. 33). La nature de l'intervention et la technique employée suggèrent une chronologie post-sismique. 
Fig. 33 - Porte d'accès à la cavea du theatrum tectum par le couloir VIII 7, 20 (porte ouest).

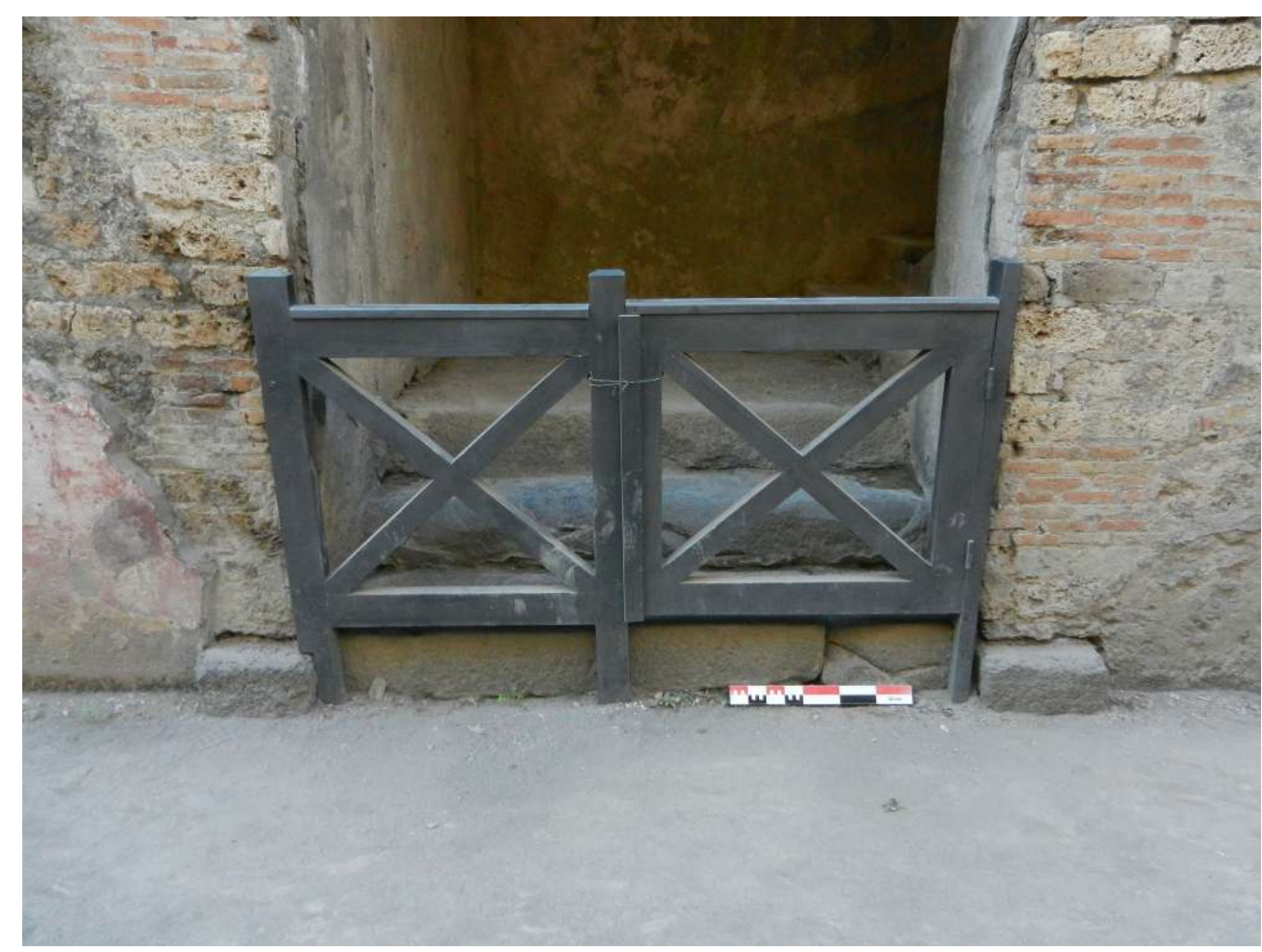

Cl. É. Letellier-Taillefer (2012). Avec l'aimable autorisation de la Surintendance de Pompéi.

66 L'ensemble des indices de remaniements dans le theatrum tectum feront l'objet de recherches approfondies dans les prochaines campagnes qui permettront d'affronter le problème de sa chronologie. Si la construction de l'enceinte est clairement située dans les premières années de la colonie pompéienne par l'épigraphie, le modèle architectural et décoratif des parties basses de la cavea renvoie à la fois à des contextes hellénistiques antérieurs (dont les autres attestations se trouvent à Sarno et Pietrabbondante) et à des innovations romaines (avec les degrés bas de la proédrie).

\section{BIBLIOGRAPHIE}

Adam 2008 = J.-P. Adam, La construction romaine : matériaux et techniques, Paris, 2008 (Grands manuels Picard).

Balty 1991 = J.-C. Balty, Curia ordinis : recherches d'architecture et d'urbanisme antiques sur les curies provinciales du monde romain, Bruxelles, 1991 (Mémoires de la classe des beaux-arts. Collection in $4.2^{\mathrm{e}}$ série, 15-2).

Byvanck 1925 = A.W. Byvanck, Das grosse Theater in Pompeji, dans MDAI(R) 40, 1925, p. 10-124.

Castrén 1975 = P. Castrén, Ordo populusque Pompeianus : polity and society in Roman Pompeii, Rome, 1975. 
Castrén $1983=$ P. Castrén, Ordo populusque Pompeianus : polity and society in Roman Pompeii, $2^{\mathrm{e}}$ éd., Rome, 1983.

Dessales $2011=\mathrm{H}$. Dessales, Les savoir-faire des maçons romains, entre connaissance technique et disponibilité des matériaux. Le cas pompéien, dans N. Monteix, N. Tran (éd.), Les savoirs professionnels des gens de métier. Études sur le monde du travail dans les sociétés urbaines de l'empire romain, Naples, 2011 (Collection du CJB 37), p. 4-63.

Dragonetti et al. 2007 = R. Dragonetti, C. Ianniello, F. Mercogliano, R. Romano, The Acoustics of two ancient roman theatres in Pompeii, dans 19th International congress on acoustics. Madrid, 2-7 september 2007, Madrid, 2007 [URL : http://www.sea-acustica.es/WEB_ICA_07/fchrs/ papers_rba02.htm].

Fiorelli 1875 = G. Fiorelli, Descrizione di Pompei, Naples, 1875 .

Gros 1996 = P. Gros, L'architecture romaine du début du III ${ }^{\mathrm{e}}$ siècle av. J.-C. à la fin du HautEmpire, 1. Les monuments publics, Paris, 1996 (Les Manuels d'art et d'archéologie antiques).

Gros 2016 = P. Gros, L'évergétisme édilitaire au temps de la seconde sophistique : le cas d'Éphèse, dans RA 62, 2016, p. 329-360.

Iannace - Trematerra - Masullo 2013 = G. Iannace, A. Trematerra, M. Masullo, The Large Theatre of Pompeii : Acoustic Evolution, dans Building Acoustics 20-3, 2013, p. 215-228.

Kelsey 1900 = F.W. Kelsey, The Stage Entrances of the Small Theatre at Pompeii, dans AJA 4-1, 1900, p. 150.

Kelsey 1902 = F.W. Kelsey, The Stage Entrances of the Small Theatre at Pompeii, dans AJA 6-4, 1902, p. 387-397.

Letellier 2015 = É. Letellier, Le théâtre dans la ville : recherches sur l'insertion urbaine des théâtres romains, thèse, Aix-Marseille Université, 2015.

Letellier-Taillefer 2017 = É. Letellier-Taillefer, Découverte, restaurations et mises en valeur des théâtres de Pompéi (XVIII ${ }^{\mathrm{e}}-\mathrm{XXI}{ }^{\mathrm{e}} \mathrm{s}$.). Enjeux documentaires, archéologiques et historiographiques, Mémoire de recherche de l'École française de Rome remis à l'Académie des Inscriptions et BellesLettres, Rome, 2017.

Maiuri 1951a = A. Maiuri, Saggi nella cavea del « Teatro grande », dans Notizie degli Scavi, ser. 8, 5, 1951, p. 126-134.

Maiuri 1951b = A. Maiuri, Risultati di saggi di scavo nel teatro grande di Pompei, dans Fasti Archaeologici 6, 1951, p. 300-301.

Maiuri 1954 = A. Maiuri, Il restauro della cavea nei teatri di Pompei, dans BA 39, 1954, p. 264-267.

Mau 1906 = A. Mau, Das grosse Theater in Pompeji, dans MDAI(R), 1906, p. 1-56.

Mazois et al. 1838 = F. Mazois, F.-C. Gau, A. Quatremère de Quincy, L. Barré, Les ruines de Pompéi. Quatrième partie, Paris, 1838.

Murolo 1959 = M. Murolo, Il cosidetto odeo di Pompei ed il problema della sua copertura, dans RAAN 34, 1959, p. 89-101.

Pagano 1997 = M. Pagano, $\mathrm{I}$ diari di scavo di Pompei Ercolano e Stabiae di Francesco e Pietro La Vega (1764-1810). Raccolta e studio di documenti inediti, Rome, 1997.

Paribeni 1902a = R. Paribeni, Pompei. Relazione degli scavi eseguiti durante il mese di agosto, dans NSA, 1902, p. 468-469. 
Paribeni $1902 b=$ R. Paribeni, Pompei. Relazione degli scavi eseguiti nel meso di settembre 1902, dans NSA, 1902, p. 512-515.

Saint-Non 1782 = J.-C. R. de Saint-Non, Voyage pittoresque ou description des royaumes de Naples et de Sicile. Seconde partie du premier volume, Paris, 1782.

Salieri et al. 2013 = R. Salieri, V. Cappellini, N. Nony, M. Pierrot-Deseilligny, E. Bardiere, L. De Luca, M. Campi, UAV Photogrammetry for archeological survey : The Theaters Area of Pompei, dans Digital Heritage, Danvers (MA), 2013, p. 497-502.

Sogliano 1906 = A. Sogliano, Esplorazioni nel teatro scoperto, dans NSA, 1906, p. 100-107.

Spano 1912 = G. Spano, Il teatro delle fontane a Pompei, dans Memorie della Reale Accademia di Archeologia 2-2, 1912, p. 109-148 et pl. I-IV.

Spano 1949 = G. Spano, Osservazioni intorno al « Theatrum tectum » di Pompei, dans Annali dell'Istituto superiore di scienze e lettere di Santa Chiara 1, 1949, p. 111-139.

Zanker 1993 = P. Zanker, Pompei, Società, immagini urbane e forme dell'abitare, Turin, 1993.

Zevi 1995 = F. Zevi, Personaggi della Pompei sillana, dans PBSR 63, 1995, p. 1-24.

Zevi 1996 = F. Zevi, Pompei dalla città sannitica alla colonia sillana : per un'interpretazione dei dati archeologici, dans M. Cébeillac Gervasoni (éd.), Les élites municipales de l'Italie péninsulaire des Gracques à Néron. Actes de la table ronde internationale de Clermont-Ferrand, 28-30 novembre 1991, Naples-Rome, 1996 (CEFR 215), p. 125-138.

\section{NOTES}

1. Sur les fouilles et restaurations de cette première période, voir en premier lieu la Pompeianarum antiquitatum historia (PAH), les Giornali di Scavo conservés dans les archives de la Surintendance et Pagano 1997. Des recherches approfondies sur l'histoire de la redécouverte de ces théâtres et de leur mise en valeur depuis le XVIII ${ }^{\mathrm{e}}$ s. sont en cours : Letellier-Taillefer 2017.

2. Une enquête récemment menée dans le cadre d'une thèse de doctorat consacrée aux liens entre les théâtres romains et les villes a permis de faire le point sur la question: Letellier 2015, p. 28-468.

3. Paribeni 1902a ; Paribeni 1902b; Mau 1906; Sogliano 1906. Les bassins découverts dans l' orchestra à l'occasion de ces fouilles sont au centre de l'article de G. Spano qui chercha à les interpréter comme l'adaptation de modèles hellénistiques: Spano 1912. Enfin l'article d'A.W. Byvanck consacré au grand théâtre (Byvanck 1925) propose une chronologie simplifiée des phases du bâtiment de scène et de la cavea qui diverge par rapport aux conclusions d'A. Mau, sans s'appuyer sur des arguments toujours recevables.

4. Maiuri 1951a ; Maiuri 1951b ; Maiuri 1954.

5. CIL X 833-834.

6. Dragonetti et al. 2007 ; Iannace - Trematerra - Masullo 2013.

7. Kelsey 1900 ; Kelsey 1902 ; Spano 1949 ; Murolo 1959.

8. Maiuri 1954.

9. CIL X 844 .

10. Balty 1991, p. 593-595 ; Zanker 1993, p. 76 ; Zevi 1995, p. 2-3； Zevi 1996, p. 130-131; Gros 1996, p. 309-310.

11. Dragonetti et al. 2007.

12. Salieri et al. 2013.

13. CIL X 833-835. 
14. Paribeni 1902b; Mau 1906, p. 42.

15. Maiuri 1951a.

16. Les moellons de tuf et de calcaire du Sarno visibles sur la face extérieure du montant occidental de cet arc correspondent à une restauration antique, potentiellement contemporaine de l'état 2 de l'aditus.

17. Les parois $O$ et $E$ de cette pièce supportent la voûte et s'appuient sur la paroi nord, enduite, qui semble uniquement composée d'une maçonnerie de moellons irréguliers de lave et pourrait appartenir à l'état 1 décrit plus haut; des recherches ultérieures dans cet espace devront préciser sa chronologie et sa fonction.

18. Le nom de cette tribune latérale, installée au-dessus de l'aditus, est ici attesté par l'épigraphie : CIL X 833-835.

19. Au débouché du vomitoire oriental de l'ima cavea, ce sol moderne recouvre une dalle de marbre.

20. CIL X 844.

21. «Caius Quinctius Valgus, fils de Caius et Marcus Porcius, fils de Marcus, duumvirs, sur décret des décurions, ont mis en adjudication la construction du théâtre couvert et ont également assuré la réception du chantier ».

22. Castrén 1983, p. 88-91, 209-210, 212.

23. Le bloc originel ne présente pas de traces d'usure. Il mesure actuellement $122,8 \times 55,5 \mathrm{~cm}$ mais pourrait avoir été plus grand: en restituant des éléments saillants très probablement retaillés, comme des ailettes latérales en partie haute et une feuillure en partie basse, on aboutit en effet à un type de seuil attesté à Pompéi (voir par exemple le seuil de l'entrée de la maison VIII 2, 26).

24. Il s'agit de tuiles de provenance locale (type A), voir Dessales 2011, p. 53-56.

25. Adam 2008, p. 143.

26. Pour des hypothèses expliquant l'assez grande largeur de ces portes latérales par leur usage pour des processions, voir Kelsey 1902.

27. Pour une série d'hypothèses concernant les portes utilisées dans ce cas pour accéder au pulpitum puis à la tribune, voir Kelsey 1902, p. 394-397.

28. Pour des réflexions en ce sens à propos des bouleuteria d'époque impériale en Grèce et en Asie Mineure : Gros 2016, p. 341.

29. Du côté oriental, sous l'escalier d'accès à la tribune, on conserve un aménagement probablement destiné à la manœuvre d'un rideau de scène, qui devra faire l'objet d'investigations spécifiques.

30. On observe tout de même quelques interventions modernes caractéristiques des premières phases de restaurations à Pompéi, effectuées avec un mortier gris couvert d'une fine couche de chaux blanche, notamment sur les écoinçons et au sommet de l'intrados de la voûte de la partie centrale.

31. L'analyse du corpus de photographies anciennes montrent que la restauration des tribunes a eu lieu entre la fin $d u X^{\mathrm{e}} \mathrm{s}$. et la première décennie du Xx $\mathrm{e}$.

32. La situation à l'est est beaucoup plus dégradée et largement issue de restaurations modernes.

33. Ce dallage n'était pas conservé dans la tribune orientale, actuellement recouverte d'une chape de ciment moderne.

34. PAH I, 2, 53-54.

35. Pagano 1997, p. 124-125; PAH I, 2, 54 (nov. 1793). Hauteur des lettres $=20,9 \mathrm{~cm}$.

36. $P A H \mathrm{I}, 3,277$.

37. Fiorelli 1875, p. 353.

38. CIL X 845.

39. P. Castrén situe l'activité de M. Oculatius Verus entre 49 av. J.-C. et 14 apr. J.-C. : Castrén 1975, n. 286, p. 199 et p. 271. 
INDEX

Index géographique : Pompéi

institutions École française de Rome, Institut de Recherche sur l'Architecture Antique (USR 3155

CNRS-AMU).

Mots-clés : Pompéi, architecture romaine, urbanisme romain, théâtre romain, odéon, aditus

Keywords : Pompeii, Roman architecture, Roman city-planning, Roman theatres, Odea, aditus

\section{AUTEURS}

\section{MYRIAM FINCKER}

IRAA - myriam.fincker@cnrs.fr

\section{ÉLOÏSE LETELLIER-TAILLEFER}

EFR - eloise.letellier@gmail.com

\section{STÉPHANIE ZUGMEYER}

IRAA - stzug@yahoo.fr 